\title{
WIND POWER AND ELECTRIC UTILITIES: A REVIEW OF THE PROBLEMS AND PROSPECTS
}

Harry Davitian

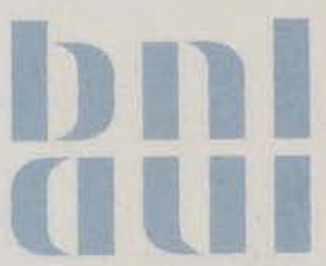

APRIL 1978

\author{
TECHNOLOGY ASSESSMENT GROUP \\ DEPARTMENT OF ENERGY AND ENVIRONMENT
}

BROOKHAVEN NATIONAL LABORATORY

ASSOCIATED UNIVERSITIES, INC.

UNDER CONTRACT NO. EY-76-C-02-0016 WITH THE

UNITED STATES DEPARTMENT OF ENERGY 


\section{DISCLAIMER}

This report was prepared as an account of work sponsored by an agency of the United States Government. Neither the United States Government nor any agency Thereof, nor any of their employees, makes any warranty, express or implied, or assumes any legal liability or responsibility for the accuracy, completeness, or usefulness of any information, apparatus, product, or process disclosed, or represents that its use would not infringe privately owned rights. Reference herein to any specific commercial product, process, or service by trade name, trademark, manufacturer, or otherwise does not necessarily constitute or imply its endorsement, recommendation, or favoring by the United States Government or any agency thereof. The views and opinions of authors expressed herein do not necessarily state or reflect those of the United States Government or any agency thereof. 


\section{DISCLAIMER}

Portions of this document may be illegible in electronic image products. Images are produced from the best available original document. 


\title{
WIND POWER AND ELECTRIC UTILITIES: A REVIEW OF THE PROBLEMS AND PROSPECTS
}

\author{
Harry Davitian
}

APRIL 1978

This report includes material previously published as THE ROLE OF WIND POWER IN ELECTRIC UTILITIES, BNL 50736, Sept. 1977; and in a paper in the PROCEEDINGS OF THE AMERICAN SECTION INTERNATIONAL SOLAR ENERGY SOCIETY, June 1977.

\author{
TECHNOLOGY ASSESSMENT GROUP \\ DEPARTMENT OF ENERGY AND ENVIRONMENT
}

BROOKHAVEN NATIONAL LABORATORY UPTON, NEW YORK 11973 


\section{NOTICE}

This report was prepared as an account of work sponsored by the United States Government. Neither the United States nor the United States Department of Energy (DOE), nor any of their employees, nor any of their contractors, subcontractors, or their employees, makes any warranty, express or implied, or assumes any legal liability or responsibility for the accuracy, completeness or usefulness of any information, apparatus; product or process disclosed, or represents that its use would not infringe privately owned rights.

Printed in the United States of America Available from

National Technical Information Service

U.S. Department of Commerce 5285 Port Royal Road Springfield, VA 22161

Price: Printed Copy $\$ 5.25$; Microfiche $\$ 3.00$ 
Table of Contents

Abstract

$\underline{\text { Page }}$

Introduction $\ldots \ldots \ldots \ldots \ldots \ldots \ldots \ldots \ldots \ldots \ldots \ldots \ldots \ldots$

vi

Potential Applications of Large Wind Machines.....

Annual Energy Available From the Wind

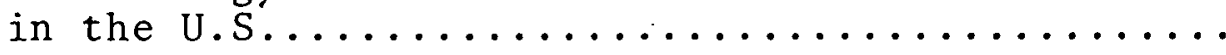

2

Wind Machine Characteristics............. 9

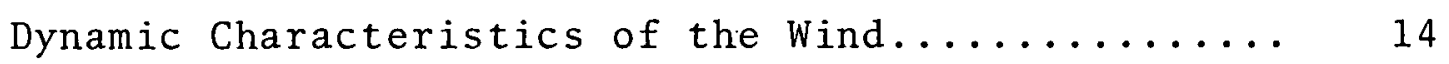

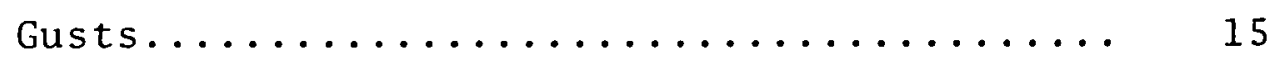

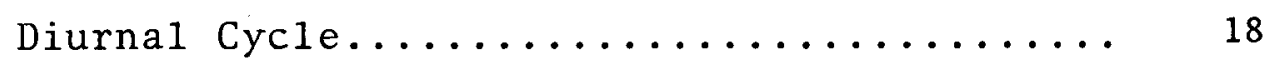

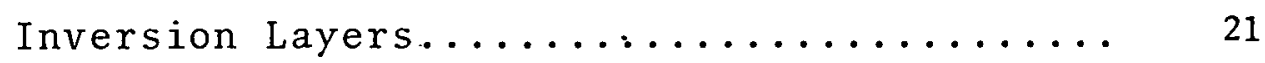

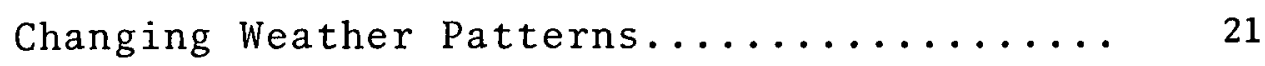

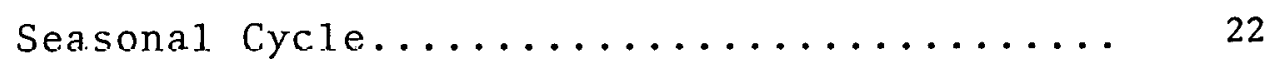

Dynamic Characteristics of Electric Utilities..... 22

Analyzing the Economics of Wind Power.......... 36

A Comment on "Capacity Credit"............. 42

Some Initial Results.................... 45

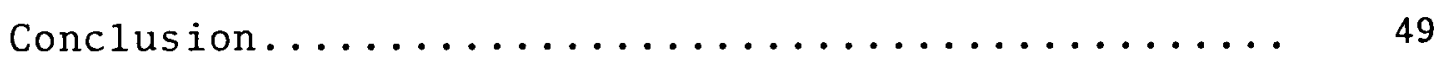

References.......................... 51 


\section{THIS PAGE}

\section{WAS INTENTIONALLY LEFT BLANK}




\section{ABSTRACT}

The upper limit on the practically exploitable energy. annually available from wind power in the United.States is roughly $1-2 \times 10^{12} \mathrm{KWh}$ per year. Electric utilities comprise the largest potential market for wind machines in the megawatt power range. The use of windpower poses a variety of problems for utilities primarily due to the uncontrollability. of the power source and the high degree of variability of the wind. Differences in the dynamic behavior of the wind and of utility load patterns and the problems that arise from these differences are described in this paper. Utility capacity expansion methods and modifications to them to incorporate the characteristics of wind machines into the analytic procedure are outlined and results from initial studies employing these modifications are reviewed. These results indicate that, in general, storage devices are too expensive to be purchased by utilities if they serve mainly to balance the output of the wind machines; wind machines tend to supplant purchases of conventional baseload capacity but require additional peaking units; and the economic value of wind machines to utilities is composed of savings in both fuel and capacity related expenditures for conventional equipment. Estimates of the value of wind machines to utilities are in the \$500-700 per kilowatt range in favorable regions of the U.S. Engineering design studies suggest that the cost of 
producing and installing wind machines might be brought down to this level with mass production and anticipated advances in design and production processes. Given the availability of high winds, the most favorable locations for the early use of wind generators are in isolated areas currently relying on small, petroleum fueled generating units and in regions with large hydropower authorities since such systems contain immense reservoirs of stored energy which could provide an ideal compliment to wind generation. 


\section{INTRODUCTION}

Wind power has several advantages as a future energy resource capable of replacing increasingly expensive and increasingly scarce fossil fuels. These are:

- no fuel requirements

- nonpolluting

- relatively safe

- advanced statc of knowledge regarding the engineering of aerodynamic, mechanical and electrical components of wind machines

However, the highly variable character of the power output and the large number of machines required to generate significant amounts of energy are serious obstacles to the largescale use of wind turbines. This paper attempts to summarize several aspects of our current understanding of the potential for and the problems associated with the use of large wind machines. In particular, the paper concerns itself with problems associated with the use of wind power by electric utilities as these utilities are the largest potential market for wind machines .

It is easy to answer the question "Can electric utilities use wind power?" The answer is an unqualified "yes" as there are no insurmountable technical obstacles to such usc. However, electric utilities will have a variety of other generating systems to choose from and whether or not they use wind power will depend on the relative economic and technical characteristics 
of wind power compared to the alternatives. Because these characteristics have so many different dimensions, such a comparison is not triviai.

Electric utilities are especially concerned about how the complex dynamic aspects of the wind might affect the stability of the power system and their ability to meet the demand for electricity at all times. In order to gain an understanding of these problems, we will explore the characteristics of wind variability on the one hand and the dynamic aspects of utility operations on the other. We will then outline the methods and results of recently completed and ongoing studies which attempt to incorporate the unique characteristics of wind machines into utility analytic techniques in order to compute realistic estimates of the economic value of wind machines to utilities.

POTENTIAL APPLICATIONS OF LARGE WIND MACHINES

The potential applications of large wind machines (greater than $100 \mathrm{KW}$ capacity) can be categorized first by the form of power output and second by type of user. The form of the power output can be either electricity (conditioned for use by conventional electrical equipment) or direct mechanical or thermal energy (where the thermal energy can be produced by a simple electric gencrator and resistance heating or by mechanical stirring) .

The use of direct mechanical power from wind machines is very limited due to the extreme variability of wind power and the constraints imposed by siting. Although small and medium- 
sized machines have found such a role as sources of power for water pumping, machines in the megawatt power range are too large for this application.

The use of wind machines to generate thermal power suffers a strong economic handicap. Generally, thermal energy sources (fuels) can be purchased for one-third to one-fifth the cost of purchased electricity -- i.e., at a comparatively low cost. Consequently, wind machines must be relatively inexpensive before they can compete in this application. Since the economic competitiveness of wind machines as generators of electricity appears only marginally favorable, their use to provide thermal power generaliy suffers serious economic obstacles. The ability to store thermal power inexpensively partly compensates for the disadvantageous variability of the wind but this benefit is insufficient to reduce the overall costs of thermal energy from wind power to a competitive level. Thus, we are left with electric power generation as the most likely use of large wind machines for the foreseeable future. Three types of users form a potential market for electricity generating wind machines: electric utilities, other large utilitics (especially water supply authorities), and industry.

The use of wind power by industry can be expected to be very limited for a number of reasons: First, the number of candidate industrial facilities is limited since most industrial plants are not located at.good wind power sites and 
since not all industries require large quantities of electricity. Second, the economics are usually not favorable to wind power because industries requiring large quantities of electric. ity are generally located in parts of the country with low cost electricity. Third, the need for backup power or storage that is available at a reasonable cost on an as-needed basis places additional cost burdens on a facility using wind power. Finally, corporate investment practices are such that capital investments in energy saving or energy generating equipment have a low priority.

Although nonelectric utilities can in some cases be favorable applications for wind energy, such applications will not, in sum, constitute a major market for large wind machines.

Electric utilities on the other hand, are in the business of generating, transmitting, and distributing electric power. Using alternative generating equipment and, where available, storage devices as backup, they are capable of accommodating the variations in wind power more easily than most other potential users. Their extensive electric transmission lines, already in place, pass through many good wind locations minimizing the cost of adding wind machines. In addition, the financing of additional generating equipment is easier for utilities than for industry. Finally, resource constraints and safety and environmental concerns are causing the costs of conventional generation to increase, favoring the examination of new generating systems. 
For these reasons, electric utilities are the largest and most likely potential market for wind machines in the megawatt power range. In the discussion that follows, we will concentrate exclusively on this application.

ANNUAL, ENERGY AVAILABLE FROM THE WIND IN THE U.S.

The power that can be extracted from the wind is limited by a number of factors. A fundamental physical limitation on wind power use is the rate at which energy extracted from winds near the earth's surface (i.e., at heights up to the machine height) can be replenished from winds at higher levels. A consequence of this is that the area density of the power extracted from the wind is limited; as each individual machine in an array is made greater in capacity, the optimal distance between machines increases. The relationship between optimal distance and machine capacity is not completely understood; current estimates are that the minimum spacing for a two dimensional array in locations experiencing isotropic wind power distributions is about ten to fifteen rotor diameters.

Practical considerations further limit wind power use. Terrain and availability of land to utilities limit the land areas that can be used. In addition, there are economic and technical constraints on wind machine size, rated capacity, and capacity factors. These constraints imp1y a limit on the minimum average wind power density that can be practically. exploited. 
When all of these factors have been accounted for, it is estimated that a maximum of some $1-2 \times 10^{12} \mathrm{KWh} / \mathrm{year}$ of electrical energy can be extracted from the winds over the land areas of the conterminous United States. ${ }^{1}$ Present total U.S. electricity consumption is about $2 \times 10^{12} \mathrm{KWh} /$ year. Thus, if wind power could be exploited to its maximum practical potential, as much electrical energy could be generated in a year as is currently consumed in the U.S.*

Annual wind energy density (i.e., the. wind power crossing a unit area, integrated over a year) varies greatly from site to site even on a small spatial scale. Thus, any description of the availability of wind power on a regional scale is bound to be general and will neglect locàl variations; excellent wind sites will be found even in regions of low average wind power density and vice versa. Bearing this spatial variability in mind, we can nevertheless gain a picture of the broad scale of wind power availability and the likelihood of finding good wind sites by dividing the wind resource into various wind regimes according to annual wind energy: density as shown in Figure 1 and then mapping a region by wind regime. Such a map of the U:S. is shown in.Figure 2 .

As can be seen from Figure 2, high wind energy areas are predominantly located offshore. Although it is believed that such sites will be considerably. more costly to exploit than

* Problems associated with dynamically matching power output to demand as discussed in later sections of this paper make the use of wind power on this scale unlikely. 


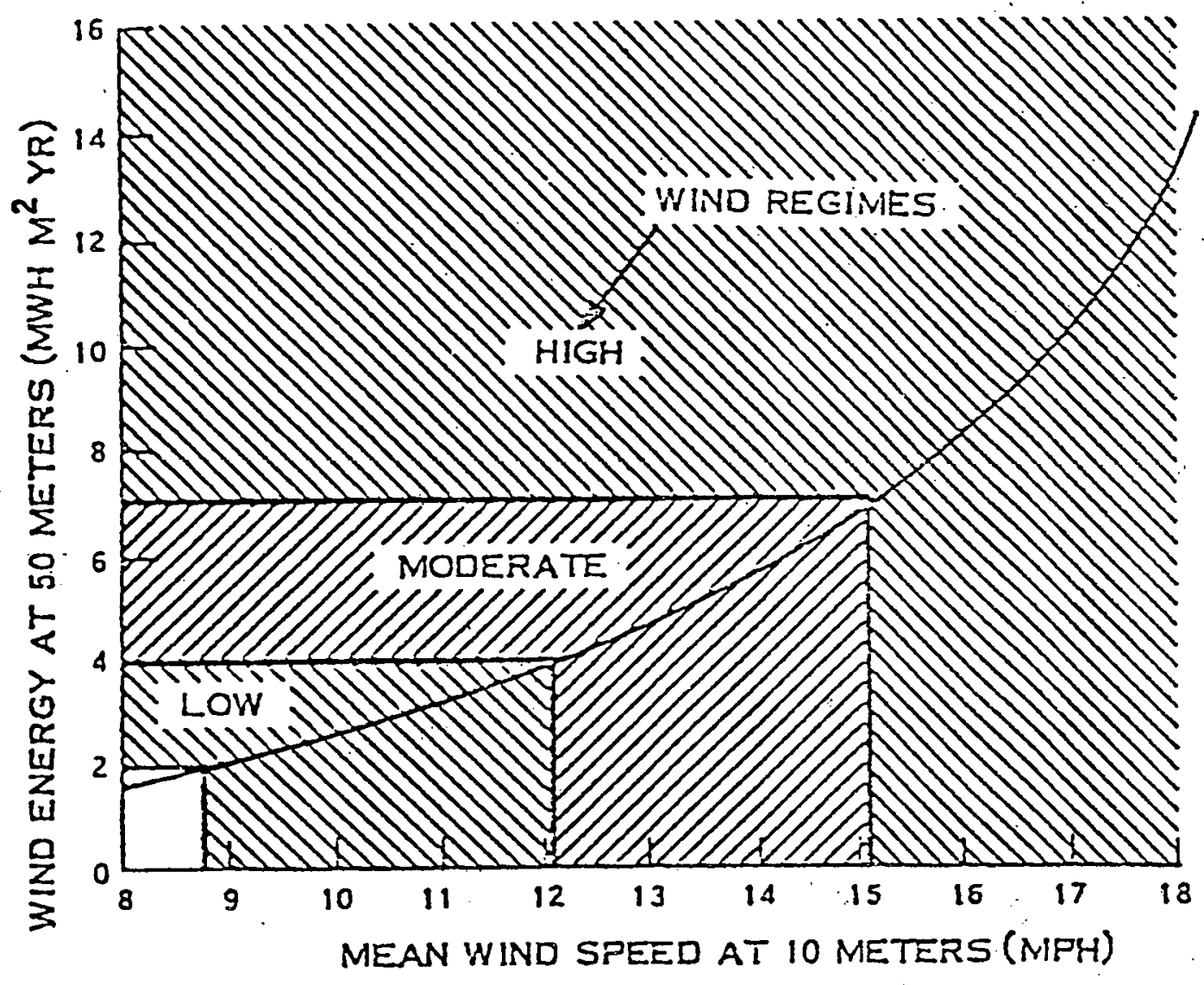

Figure 1. Relationships between annual wind energy density, wind regime, and mean wind velocity.

Source: Reference 1. 


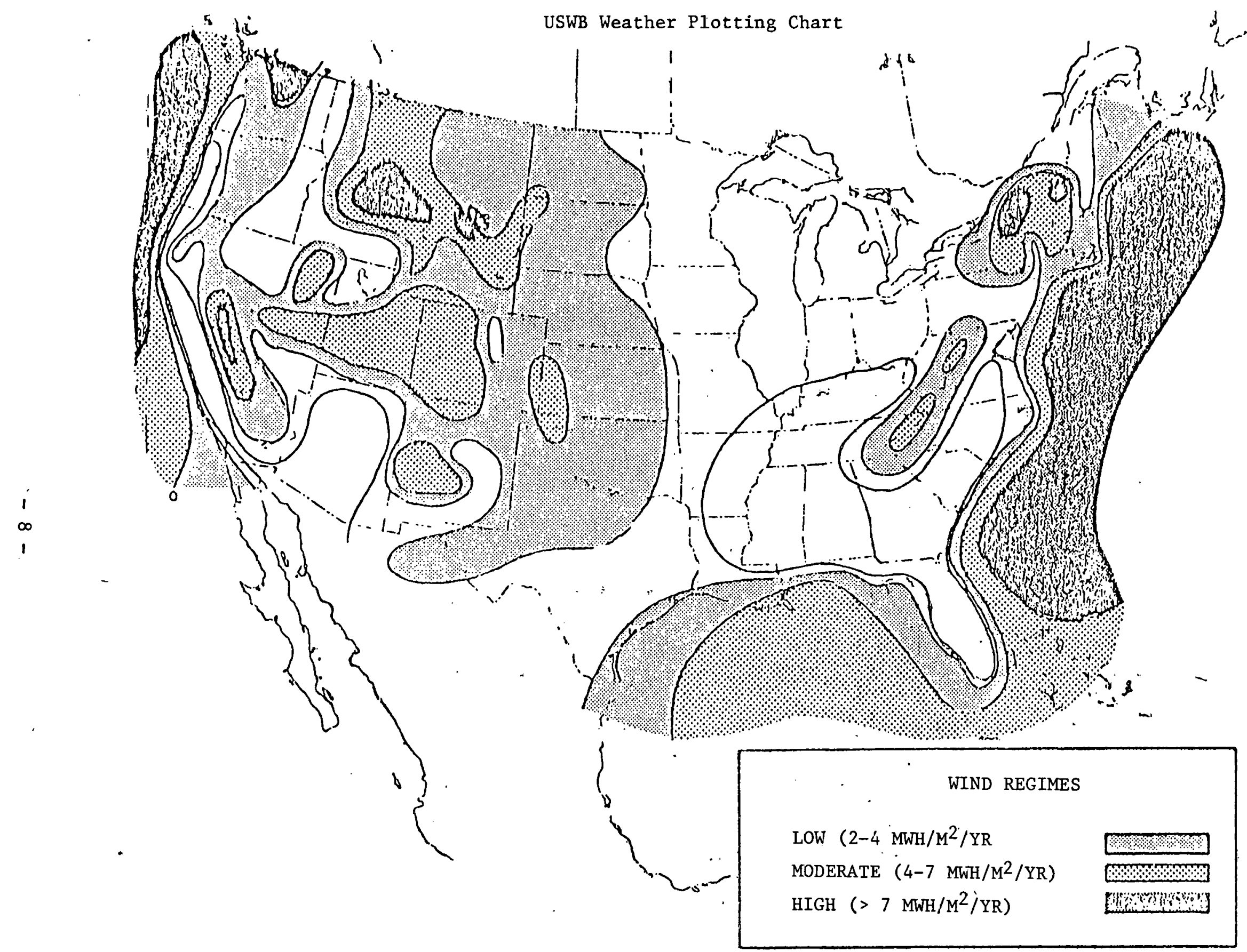

Figure 2. Favorable wind regimes. 
onshore locations, little quantitative information is available as yet regarding the overall costs of delivering power from offshore wind machines to load centers onshore. Because of this paucity of information, offshore generation of wind energy is not discussed in this paper.

Few areas of high wind power density exist onshore and these few are concentrated in mountainous areas. These high wind areas are likely to be among the first exploited for power generation but because of their limited extent and because of various barriers to the use of this land for wind power generation,* such areas will not contribute significantly to electricity generation in the U.S. The moderate wind energy regime covers a much greater land area than the high regime and hopes for the large scale use of wind power in the U.S. must rest with the development of wind machines capable of economically exploiting winds with mean velocities in the 12-15 miles per hour range characterizing the moderate regime. Roughly half of the total practically exploitable wind power in the U.S. is located in the moderate regime.

WIND MACHINE CHARACTERISTICS

The vast majority of wind machines built historically had power ratings in the kilowatt and subkilowatt range. From a contemporary utility perspective, considerably larger machines are necessary to reduce the overall costs of site selection,

*For example: terrain limitations, long distances to transmission 1 ine interties, poor access to sites, national park status. 
site preparation, installation, maintenance, access roads, transmission lines, protective switchgear and machine components. Increasing machine size from 0.5 to $1.5 \mathrm{MW}$, for example, can halve the cost of transmission lines and protective switchgear. ${ }^{2}$ Although there are a multitude of machine design possibilities (e.g., Savonious, Darrieus, vertical-axis articulated blade, American farm windmill, diffuser augmented turbine) only the familiar propeller type, horizontal-axis machine has proven its potential for operation in the megawatt power range. ${ }^{*}$ Wind generators deployed by utilities in the near future, and in particular, the machines to be installed b.y the Department of Energy (DOE) on various utility systems will employ this design concept and are likely to be characterized by a twobladed, horizontal-axis rotor with a diameter of 150-300 feet, blade pitch and yaw controls, a rotation frequency of 30-60 rpm, and a 0.2-3.0 MW rated capacity, constant speed, synchronous generator. The key factor constraining the size of these machines is expected to be bladc structure technology.

Even the largest wind generators now envisioned, 1.5-3.0 MW in rated capacity, are still very small by contemporary utility standards. New coal or nuclear-fueled generators have power ratings of about $1000 \mathrm{MW}$. The simplicity of the wind generator in comparison to these hugh and complex

* Recently, the Canadian Government has installed a $230 \mathrm{KW}$ rated Darrieus wind generator at a site on the Magdallen Islands. The performance of this machine should help clarify the potential applicability of this design to the large machine category. 
plants is counterbalanced by the need for large numbers of machines: on an annual basis, about 15001.5 MW units, operating at a capacity factor of roughly 0.35 , would be needed to produce as much energy as one such coal or nuclear plant. The protective switchgear, monitoring equipment and transmission interties required for reliable utility operation, plus land leasing or acquisition for so many machines add substantially to the basic machine cost.* In addition, power outages due to a lack of wind are more frequent than forced outages due to conventional plant breakdowns so that greater reserve requirements are likely to be needed with wind power.

A variety of mechanical to electrical power conversion schemes have been proposed for use on wind machines. These include: ${ }^{4,5}$.

- DC generator with inverter

- Variable shaft speed constant electrical

frequency $A C$ generator

- Induction generator

- Synchronous generator

The primary advantage of the first two is that they are, in principle, somewhat more efficient since they permit.wide variations in the speed of the rotor and thus have a higher aerodynamic to mechanical power factor. However, they are heavier and more costly than the induction and synchronous *In a recent study, ${ }^{2}$ it was estimated that costs for transmission lines and protective switchgear along range from about $\$ 100$ to $\$ 300$ per $\mathrm{KW}$, depending on the number of units in an array, the spacing between units, and the distance to the grid intertie. 
generators which require nearly constant and exactiy constant speed operation respectively; the gain in efficiency may be outweighed by these and other factors. The constant speed, synchronous generator is currently favored due to a combination of beneficial features:

(1) The potential for resonant structural vibrations coupled to the low rotor frequency is minimized by having a constant rotor frequency.

(2) The generator places no reactive power demands upon the grid.

(3) It is a well known technology.

(4) Its weight is less than that of most alternative schemes.

(5) It has favorable stability characteristics (see "Effects of Wind Variations," below).

Several machine design studies, $6,7,8$ have focussed on developing specifications for machines which minimize the cost of electricity generated. The design problem is complicated by the difficulty of estimating cost-performance characteristics of the machine components. For example, production costs vary as a function of production quantity so that machine component costs are highly dependent on whethor the total production run is 10 units or 1000 units. Design studies to date indicate that the optimized design should have a performance curve as shown in Figure 3. Below the cut-in velocity, no net power can be delivered to the grid and the machine 


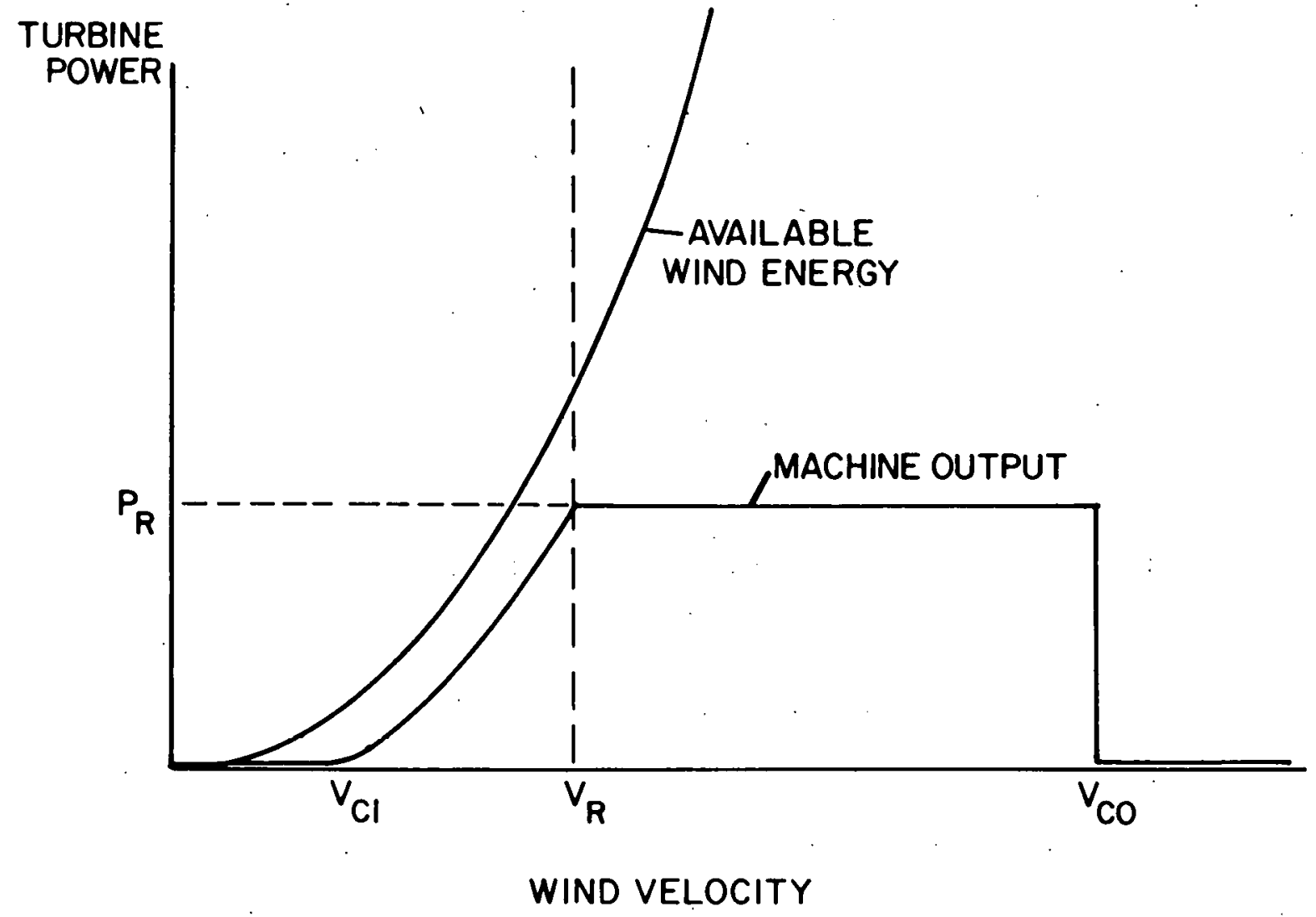

Figure 3. Characteristic machine response. 
does not operate. Above the rated velocity (corresponding to the rated capacity of the generator) blade pitch is adjusted to maintain a constant output. Typically, the cut-in velocity is roughly half the rated velocity and the rated velocity is slightly higher than the mean wind speed for which the machine is being designed. Although it may appear from Figure 3 that vast quantities of energy are being lost at the higher wind velocities due to the plateau in the performance curve, the frequency distribution of the wind velocity is such that winds seldom blow at the higher velocities and a relatively small fraction of the total energy is contained in such winds. Above some velocity, the cut-out velocity, the machine is shut down to avoid damage from high winds. As an example of the results of design studies, it is estimated that a $1.5 \mathrm{MW}$ machine optimized for an $18 \mathrm{mph}$ mean wind speed would have a capacity factor of roughly 0.35 and would produce about $7 \times 10^{6} \mathrm{KWh}$ per year. ${ }^{1}$

DYNAMIC CHARACTERISTICS OF THE WIND

From a utility perspective, the single most distinguishing feature of wind power is its variability. Wind power varies on a variety of time scales due to several causative factors as outlined in the lable below: 
Cause of Variation

Gusts (turbulence)

Diurnal cycle

Inversion layers

Changing weather patterns

Seasonal cycle

Variations in annually

integrated wind power
Time Scale of Variation

Sub-second to second

Daily

Hours

Hours (period for front to pass)

Days (period from one pattern: to another)

Seasonal

Years

A11 of these variations can affect utility operations and each must be carefully considered in the process determining the value of wind power to a utility. Although several of these factors also indirectly affect utility operations (e.g., diurnal and seasonal cycles affect the utility load, weather patterns and seasonal cycles affect hydropower availability), the potential effects on a utility of variations in the output of wind machines are considerably more severe.

We will now discuss these different types of variations in more detail to show how they can affect utilities:

\section{Gusts}

Gusts will affect single wind machines and can cause them to go out of synchronization with the grid. This can occur if the rate of change of power in the wind due to the gust is greater than the capability of the machine's control system to reduce the torque impulse acting on the generator. Typical 
gust profiles with various probabilities of occurence are shown in Figure 4. The curves in Figure 5 indicate maximum torque and power changes expected for time scales most likely to be of concern from a power system stability viewpoint; gusts with periods in the neighborhood of 0.6 to $0.8 \mathrm{sec}$. can produce $100 \%$ variations in torque in 0.3 to 0.4 seconds. Such transients can result in loss of synchronization fur a wind machine which would lead to the activation of the protective switchgear for that machine and its temporarily being disconnected from the grid. Such an occurrence would have minimal effects if it occurred infrequently, particularly if the wind machine were part of a large system. However, frequent machine outages of this type, especially if they occurred on a large array of wind machines, would be considered disruptive and utilities may require that the wind machine's control system be adequate to reduce the frequency of loss of synchronization to very low levels.

Preliminary results from an on-going simulation study of this problem ${ }^{9}$ indicate that induction generators are unsatisfactory from a stability standpoint. Given current conceptions of their control systems, synchronous generators are expected to be stable in steady winds, marginally stable with small to moderate gusts, but to cxhibit unacceptable performance with strong gusts (with a likelihood of occurrence of several times per year). The preliminary conclusions suggest that improved control systems and added damping can 


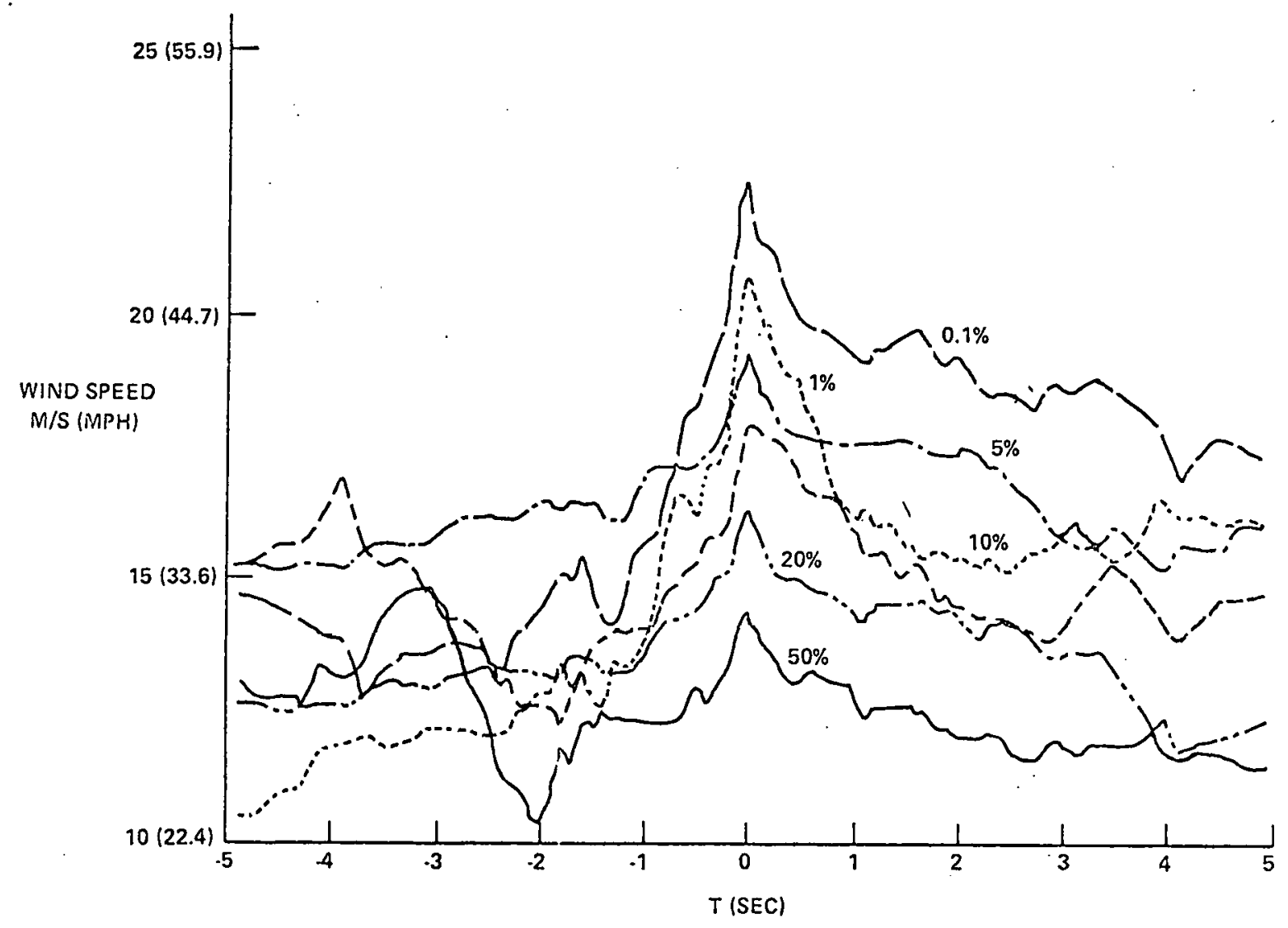

Figure 4. Wind gusts profiles. Source: Reference 9.

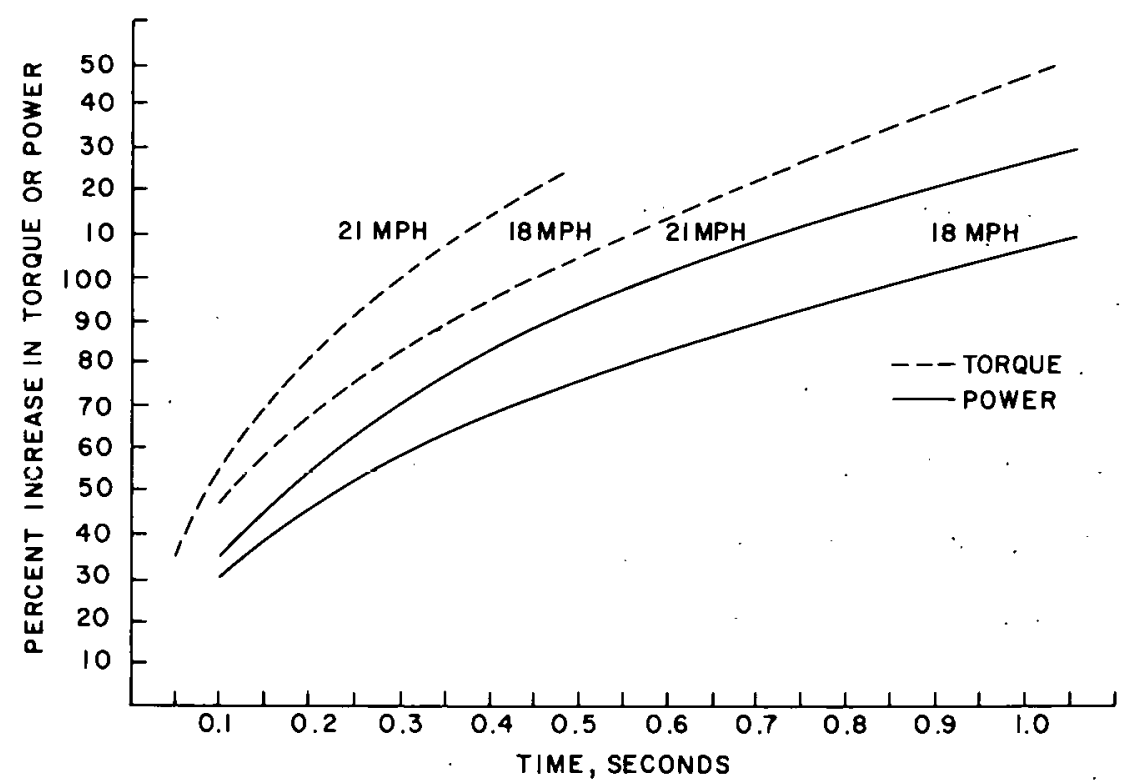

Figure 5. Envelopes of maximum torque and power pulses vs. time. Source: Reference 9. 
improve performance to a level acceptable to utilities. In particular, an upwind anemometer and an optimized power system stabilizer referenced to hub speed were suggested as especially desirable additions. Wind sheer, inflow effects and tower shadow effects are not expected to affect controlability.

\section{Diurnal Cycle}

Changes in the thermal energy input to the atmosphere due to earth's rotation result in a diurnal variation in wind power. Characteristic daily cycles for hourly wind energy are shown in Figure 6 for the three wind regimes. There are broad peaks in wind power in the early afternoon in the low to moderate regimes and a minimum during this same period for the high wind regime. In Figure 7, a typical daily load curve for a utility is shown. Note the rough correspondence between the wind power output curves for the low and moderate wind regimes and the daily load curve. This correspondence has important consequences regarding the technical and economic feasibility of wind power use by utilities. Briefly, generating units with the highest costs of generation per KWh and the most flexibility in output are added to the system during the daily peak load periods. If the bulk of wind energy were available during these periods, then the economic competitiveness of wind power would be improved since the marginal costs of conventional generation are highest"during the "peak period. Also, the 


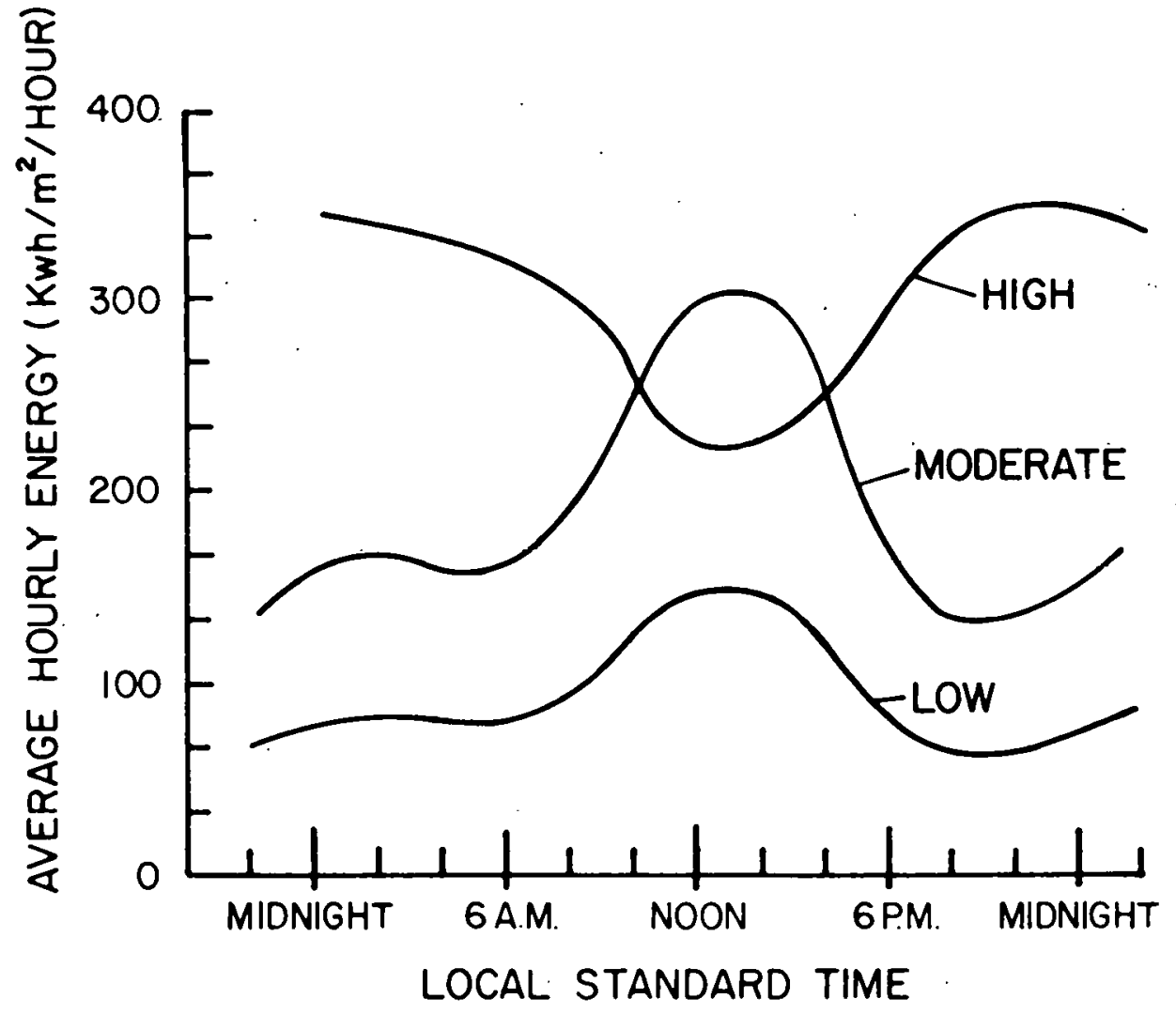

Figure 6. Diurnal variation of wind energy in the three favorable wind regimes. Source: Reference 1. 


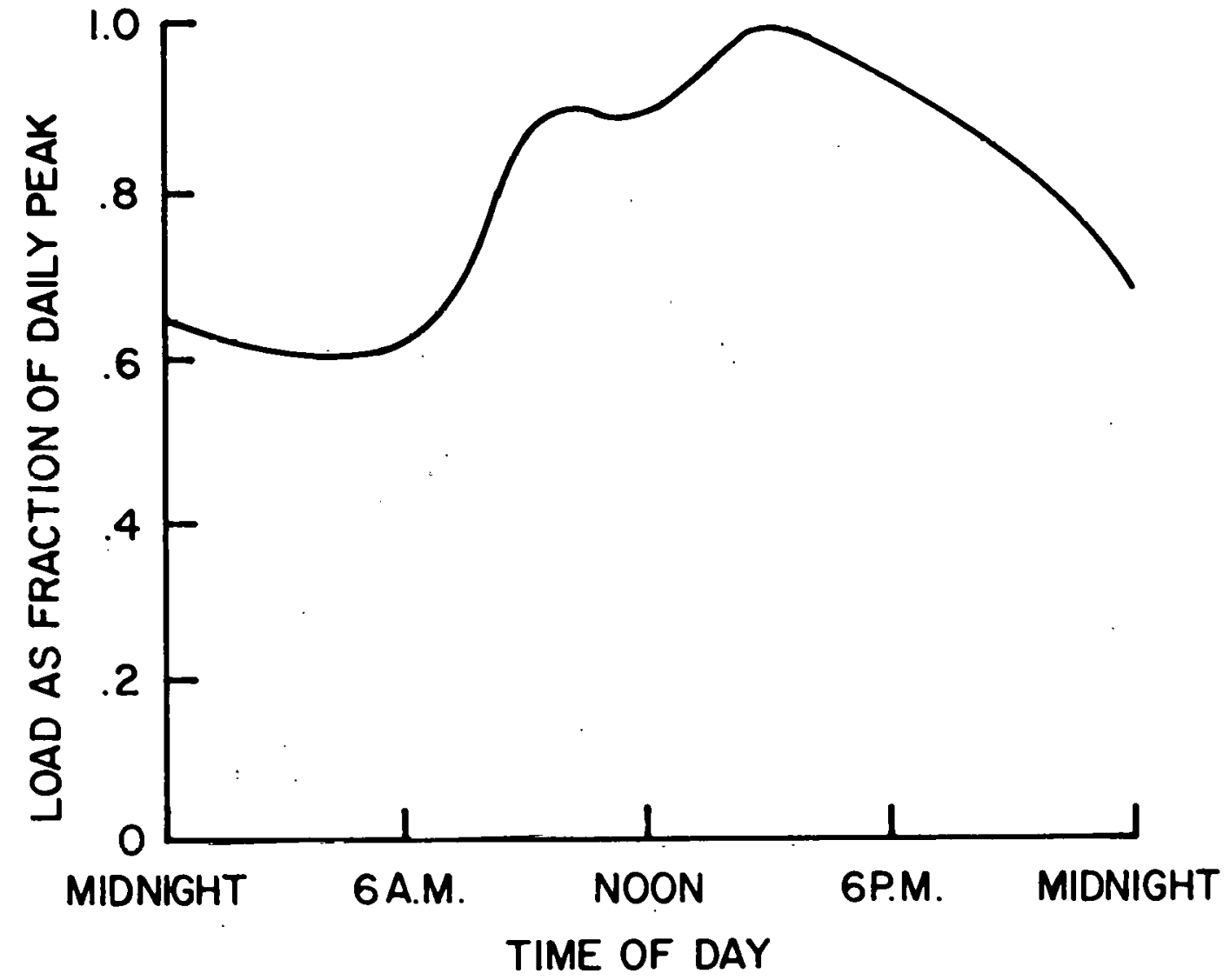

Figure 7. Daily cycle of 1oad. Source: Reference 1. 
incorporation of this variable supply is made technically easier due to the flexibility of the peaking units. These considerations are amplified in a subsequent section.

Inversion Layers

Atmospheric thermal inversions can occassionally result in horizontal boundary layers below which wind speeds are low and above which they are high. These boundary layers can rise or fall in altitude as atmospheric conditions change. If such a boundary layer intersects the cross section of a wind turbine or an array of turbines as the layer rises or falls, large changes in power output over time scales of hours can result. Utilities using wind power must be capable of varying the conventional portion of their generating equipment to adjust to these variations.

\section{Changing Weather Patterns}

Weather patterns are typically sustained over a region for periods of several days. Since winds are closely coupled to weather patterns, periods of high and low winds will also typically be maintained for periods of several days and will alternate at frequent but irregular intervals. Consequently, the contribution of wind power to the daily cycle is irregular. and undependable.

When weather patterns do change, fronts can move across a region over a period of a few hours. Hence, as with the inversion layers above, large changes in the power output of wind machines can be experienced over a period of hours. 


\section{Seasonal Cycle}

Wind power also displays a strong seasonal dependence as shown in Figure 8 . The monthly total wind energy output of a wind machine can vary by over a factor of two from minimum to maximum on a seasonal basis. It is at a maximum during the winter months. The seasonal load patterns for utilities vary and generally fall ințo one of two categories: summer peaking or winter peaking. The seasonal characteristic is usually determined by the relative use of air conditioning, electric heating and the seasonal dependence of electric lighting. By the logic of the preceding discussion of daily cycles, wind energy is more likely to be favored by a winter peaking utility than a summer peaking utility.

\section{DYNAMIC CHARACTERISTICS OF ELECTRIC UTILITIES}

As we have just seen, temporal variations in wind power can be troublesome for utilities. In this section, we will discuss the dynamic characteristics of utilities in more detail to develop an understanding of the economic consequences of wind power variations. First we consider the nature of the load that the utility must satisfy, then we will review the generating equipment choices a utility has available to meet the load.

An electric utility attempts to generate, transmit and distribute electricity to instantaneously meet a dynamically varying load within certain limits of reliability and at the lowest cost. The temporal variations in the load are roughly 


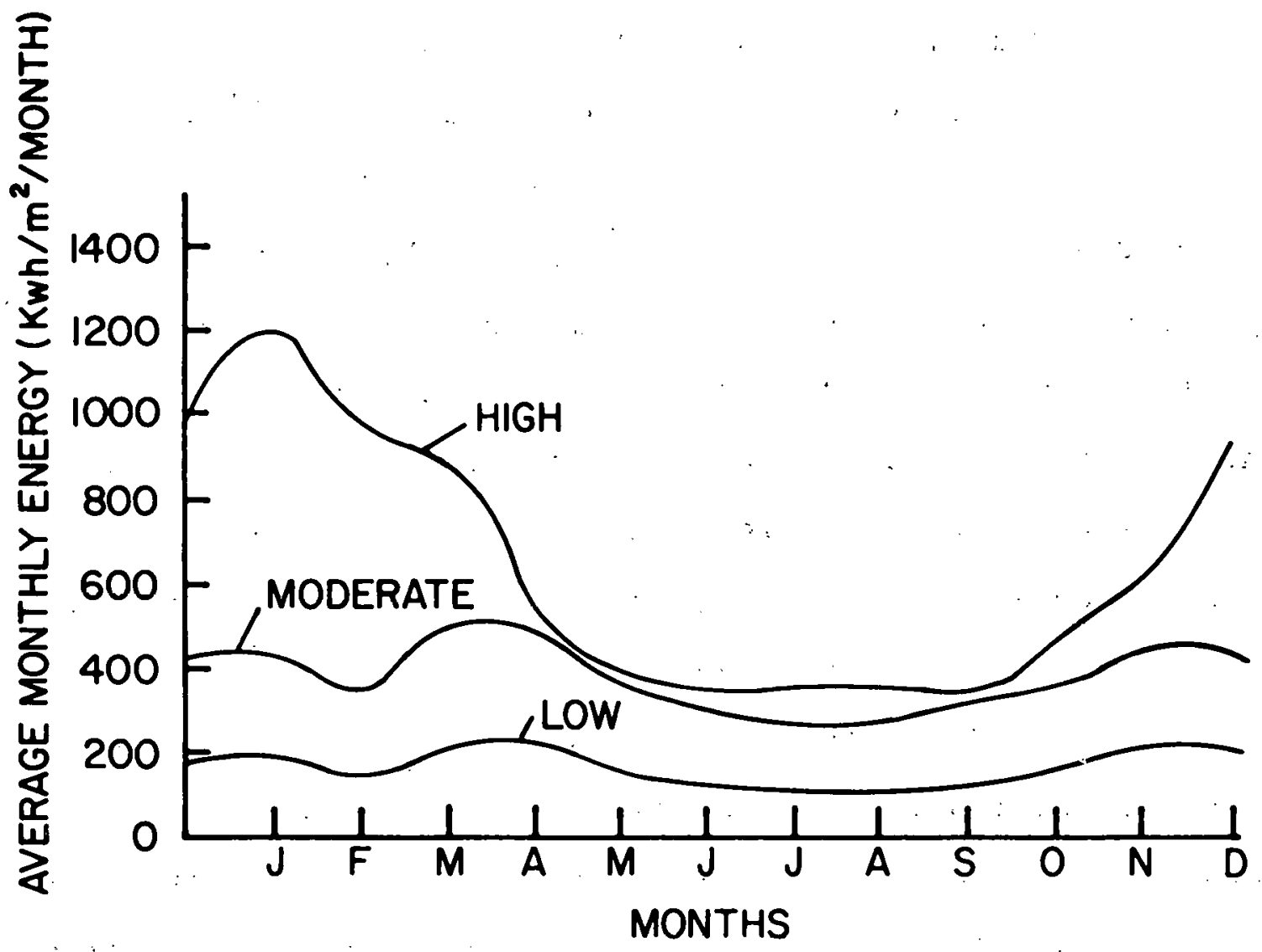

Figure 8. Seasonal variation of wind energy in the favorable wind regimes.

Source: Reference 1. 
periodic with daily, weekly and annual cycles. A typical daily profile has already been shown in Figure 7 . A characteristic weekly cycle is shown in Figure 9; note the similarity in the Monday thru Friday daily cycles and the lower weekend peaks. A typical annual cycle is shown in Figure 10 for a summer peaking utility indicating the annual maintenance schedule. Depending on the utility and the time of year, the amount of variation in load over a day can range from $20 \%$ to over $50 \%$ (relative to the daily peak load). The amount of variation over a year is usually greater than $60 \%$ (relative to the annual peak). In addition to these predictable cyclical variations, there are random weather related variations which are due to changes in heating and lighting levels. Finally, there are random variations due to the statistical nature of the load; it is composed of a very large number of electricity consuming devices which are each individually controlled. This statistical variation is generally a small fraction of the total load.

A time-dependent load curve can be compressed into an integrated form known as a load duration curve which is useful for utility planning purposes. An annual load duration curve, shown in Figure 11, indicates the number of hours per year that the load is greater than a given level.* The intercept of the load duration curve with the ordinate is the peak load of the year. The level of the load experienced at least

*The meaning of the curve can be more easily conceptualized if the axes are mentally interchanged so that the "load" axis, the independent axis, is thought of as the abscissa. 


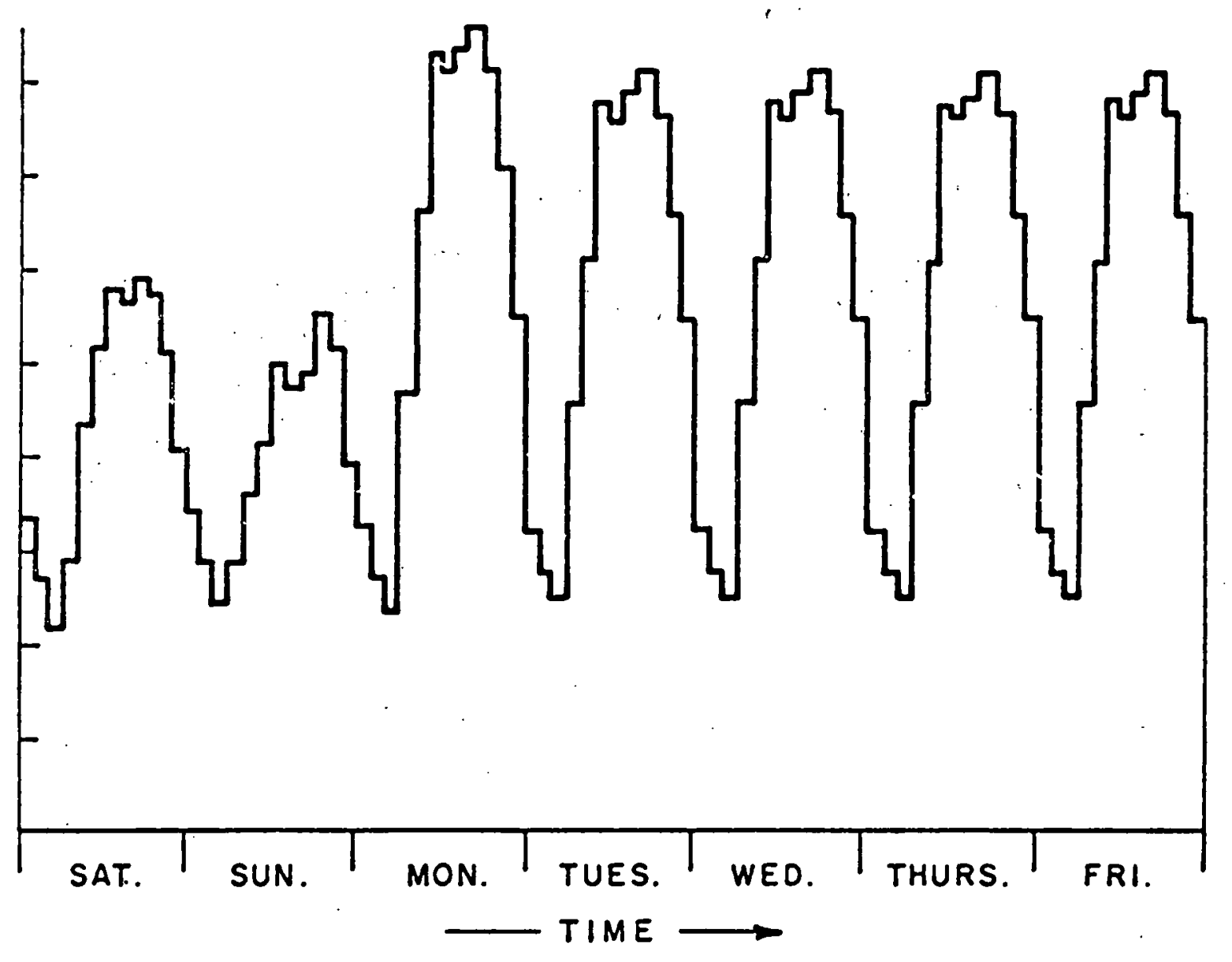

Figure 9. Weekly load profile.

Source: Reference 1. 


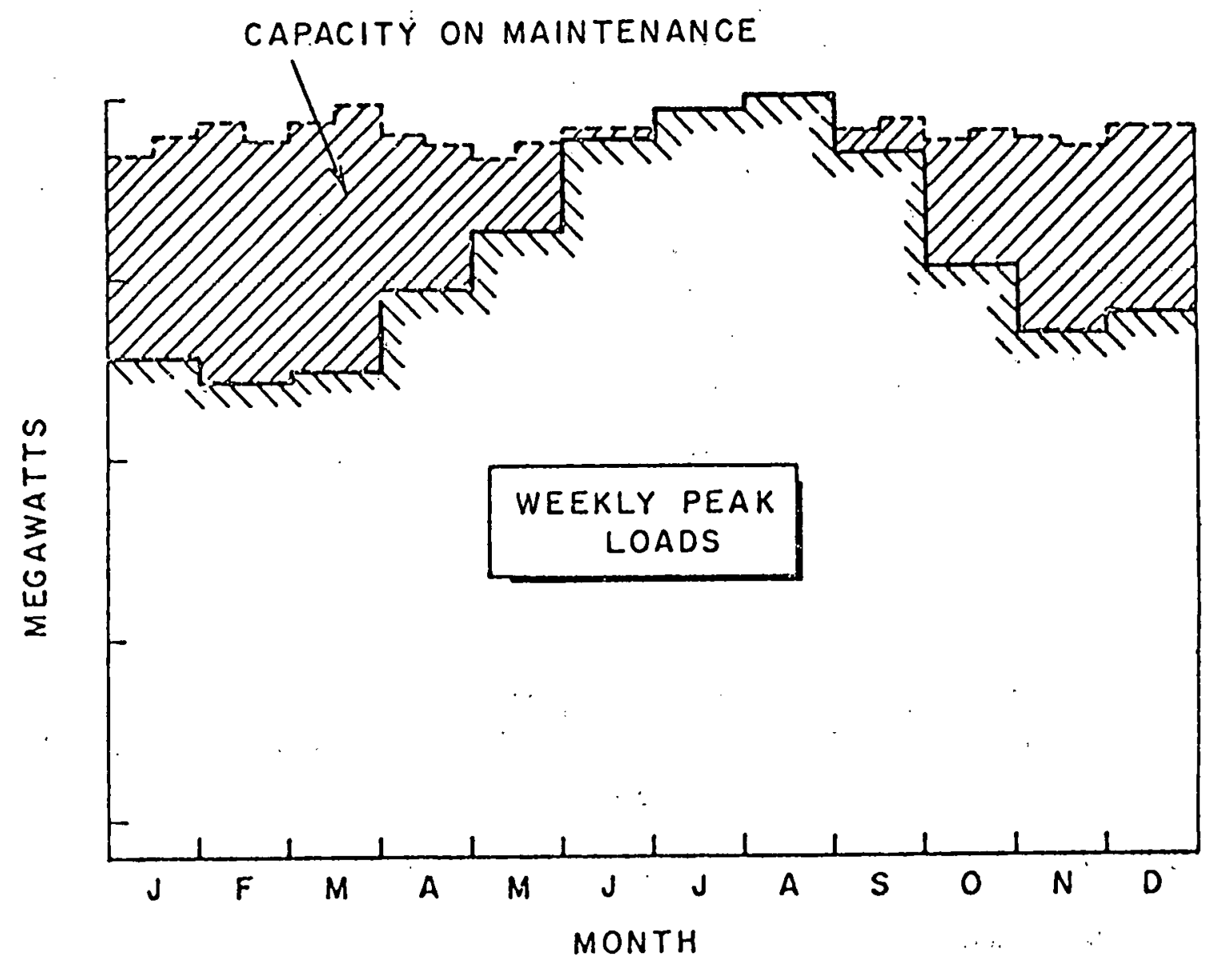

Figure 10. Annual profile of load for summer peaking utility.

Source: Reference 1. 


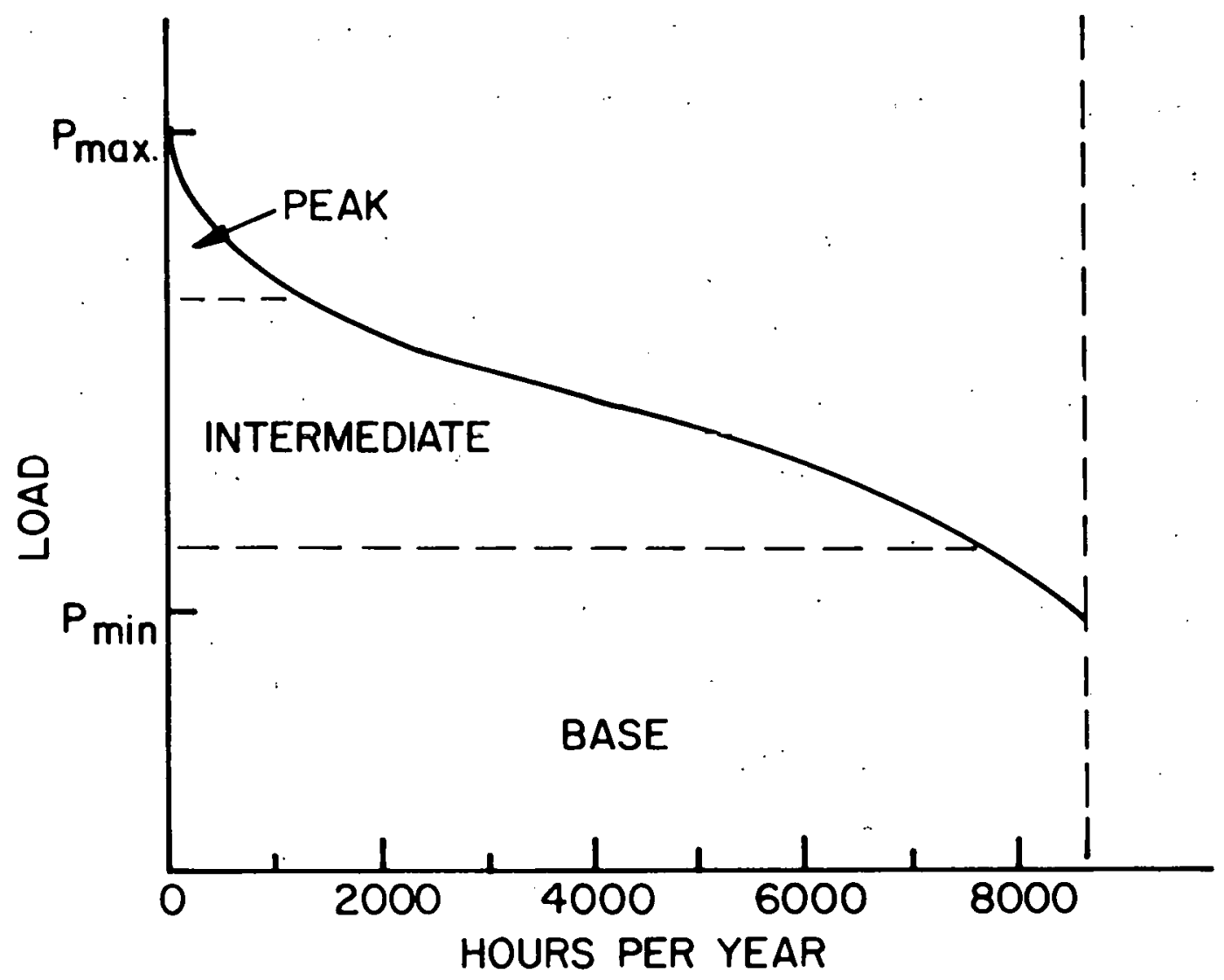

Figure 11. Load duration curve. 
8760 hours (a full year) is the minimum load; i.e., the load never drops below this level during the year. The "base," "intermediate," and "peak" categorization scheme is closely tied to the generating equipment characteristics which are discussed next.

To meet the demand for electricity, utilities have available a variety of plant types: e.g., nuclear, coal, steam, oil steam, gas turbine, diesel, and hydro. These plant types differ in a variety of characteristics, the most important of which are:

- Rated capacity of single unit

- Capital costs per installed unit of capacity

- Operating and maintenance costs per unit of electricity generated

- Fuel costs

- Reliability

- Environmental, health and social effects The age of a given plant will also affect its costs and performance; in general, older plants of a given type are less efficient and cost more to operate.

In planning future purchases of generating equipment, a utility will be concerned with defining precisely its needs for additional generating capacity (such as with a load duration curve) and choosing the least cost combination of plants to provide that capacity while maintaining the desired minimal level of overall system reliability. The problem is complicated 
by uncertainties in load growth, in new plant costs, in fuel costs and also since there is some degree of flexibility in the manner in which both old and new plants can be used. In addition, the purchase of electricity from power authorities or from other utilities (for resale to utility customers) is often an additional option.

An illustrative example* of the estimated cost structure a utility might be faced with in considering new plant purchases is shown in Figure 12. In this figure, the annual cost per unit of capacity purchased is plotted as a function of the number of hours per year that the plant will be used. It is clear from this plot that there are significant variations in the total annual costs for different plant types depending on the number of hours.per year the plant is operated. Coal and nuclear plants are favored for base load operation (high annual plant factor) while gast turbines are favored for peak load operation (low annual plant factor).

A simplified analysis of capacity expansion (i.e., future plant purchases) can be conducted with load duration curves and information of the type presented in Figure 12. The useful1ness of the load duration curve in this regard derives from the dependence of the total annual costs for different plant types on the number of hours per year that the plant is operating. Portions of the projected future load duration curve

* This example is for illustrative purposes only; cost assump= tions are not necessarily accurate.

+"Gas" turbines almost always burn distillate petroleum fuel. The adjective "gas" distinguishes these turbines from hydro turbine units. 


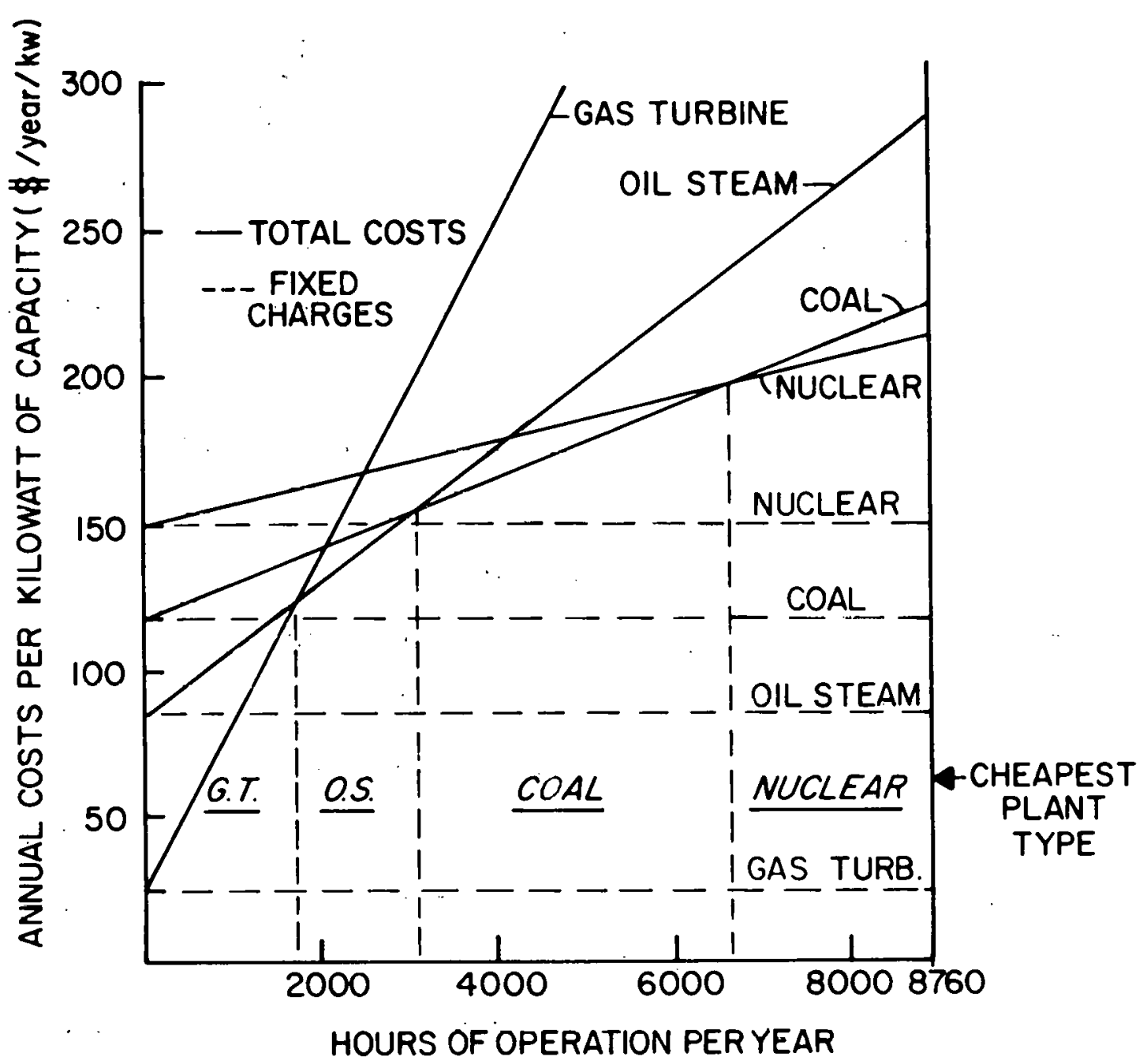

Figure 12. Illustration of variation in annual operating costs as function of annual operating hours for several plant types. 
can be assigned to various plant types, both existing and contemplated, according to which plant type has the lowest annualized cost for that portion of the load curve. This yields the first approximation to the economically optimal combination of plant types. This process is illustrated in Figure 13. Dispatching, reliability, and other considerations and the carry-over of existing plants can then be added to the analysis to produce a schedule of plant purchases which will come closest to achieving the lowest total annualized cost while meeting technical and institutional constraints.

Once plants have been purchased, their dispatch (scheduling of their use on a fine time scale) depends only on. variable (operating and fuel) costs since capital amortization and taxes must be paid independently of use. Variable costs for the different plant types are displayed in Figure 14. Note that hydro, wind and solar plants, with no fuel costs, have very low variable costs while gas turbines, which use expensive fuel inefficiently and incur high operating costs, have high variable costs. An important constraint on dispatching. is that changes in the output of large steam plants should be made slowly and that operating them at part load is inefficient; in practice, these plants are not varied very much on a daily basis - they are "base loaded." A simplified description of the strategy of dispatching thus follows the scheme outlined below as the load increases:

(1) First load the minimum level of the large nuclear and fossil steam plants and the minimum hydro permitted. 
CONVENTIONAL

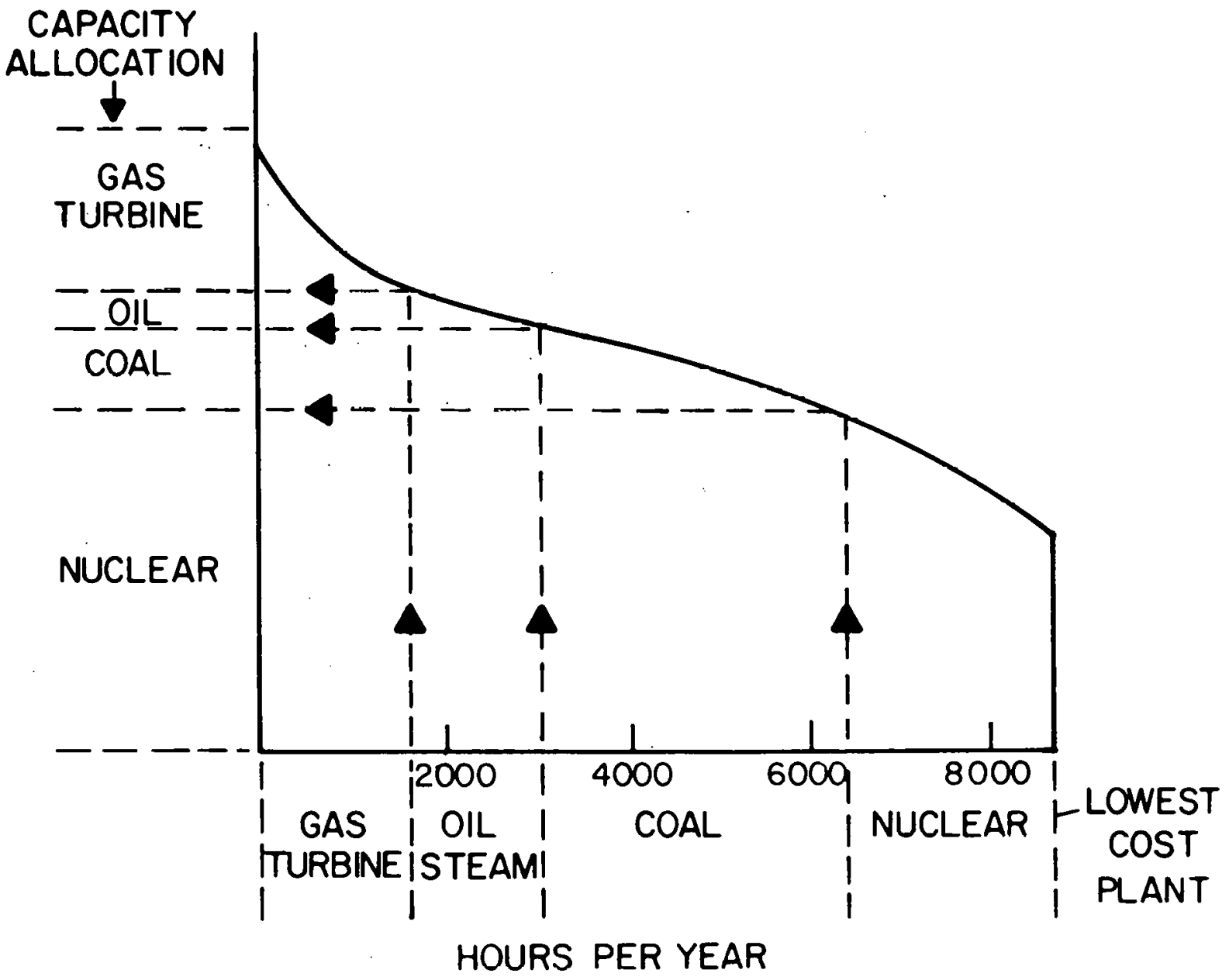

Figure 13. Optimal capacity allocation using load duration curve. 


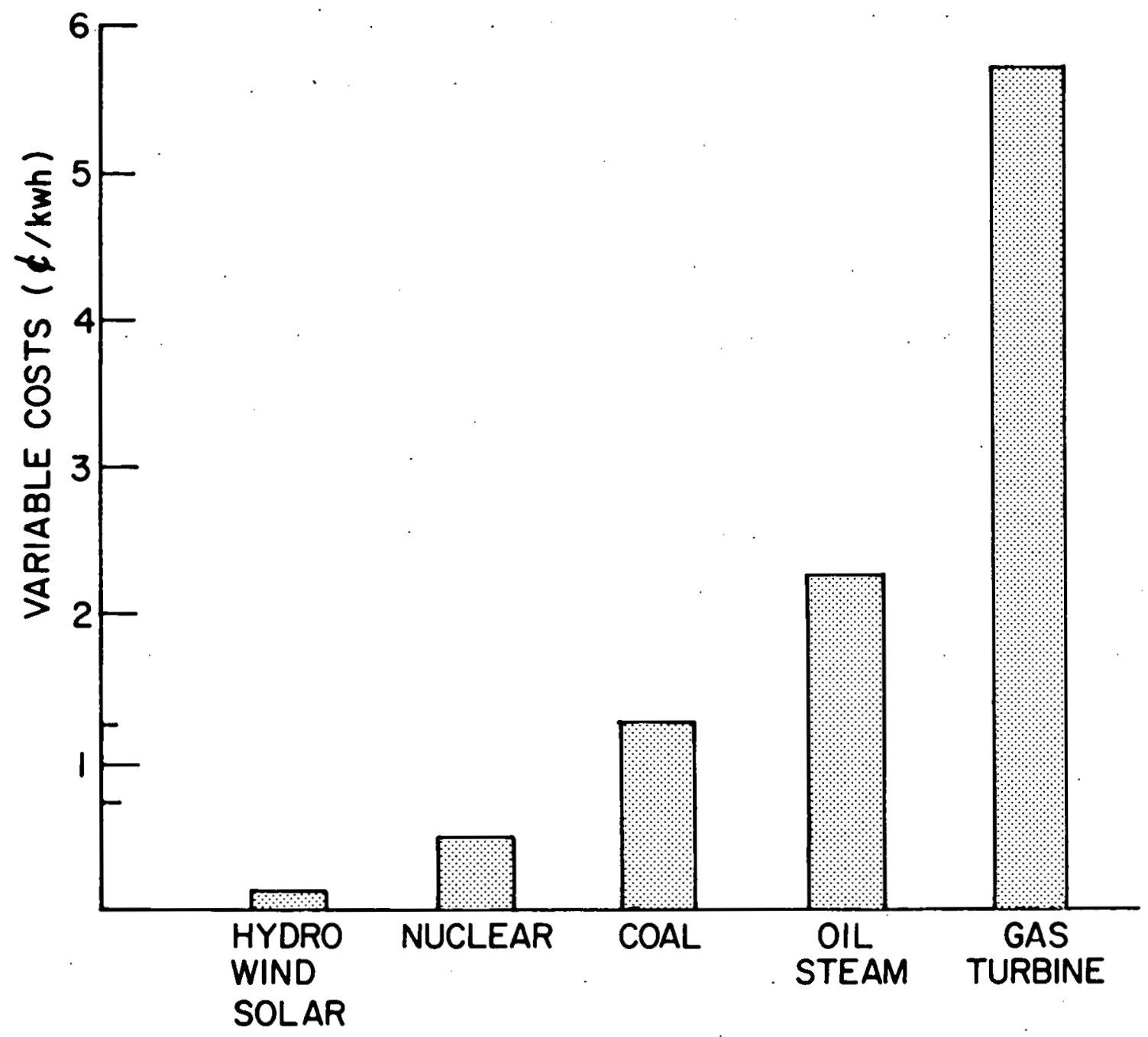

Figure 14. Variation in variable costs by plant type. 
(2) If the load is greater, increase the level of the large baseload plants to their maximum 1 evel.

(3) If the load is greater, add smaller intermediate cycling plants.

(4) During peak periods, add peaking units, such as diesels, gas turbines, pumped hydro, stored hydro.

This dispatching scheme is illustrated in Figure 15.

If wind power is available, the output of other plants would be reduced in the opposite order depending on the amount available, down to the minimum levels. It should be clear by now why wind energy is most beneficial if it is generated primarily during the daytime peaks; during these periods, the utility experiences the highest variable costs per unit of electricity generated. Conversely, wind energy is worth much less at night and may actually have to be wasted if the wind power output is greater than the difference between the load and the minimum output of the large steam and hydro plants.

We should emphasize that this discussion of utility operations is highly simplified and ignores many important aspects of utility operations. Reliability considerations, for example, requiring that spinning reserve be available to compensate for instantaneous outages alter the simplified dispatching scheme presented. Also, it should be remembered that utilities vary a great deal and that not all the plant types mentioned may actually be employed; in some cases, for example, hydro power is the only generating source. Finally, large computer programs have been developed in the past decade which generally combine 


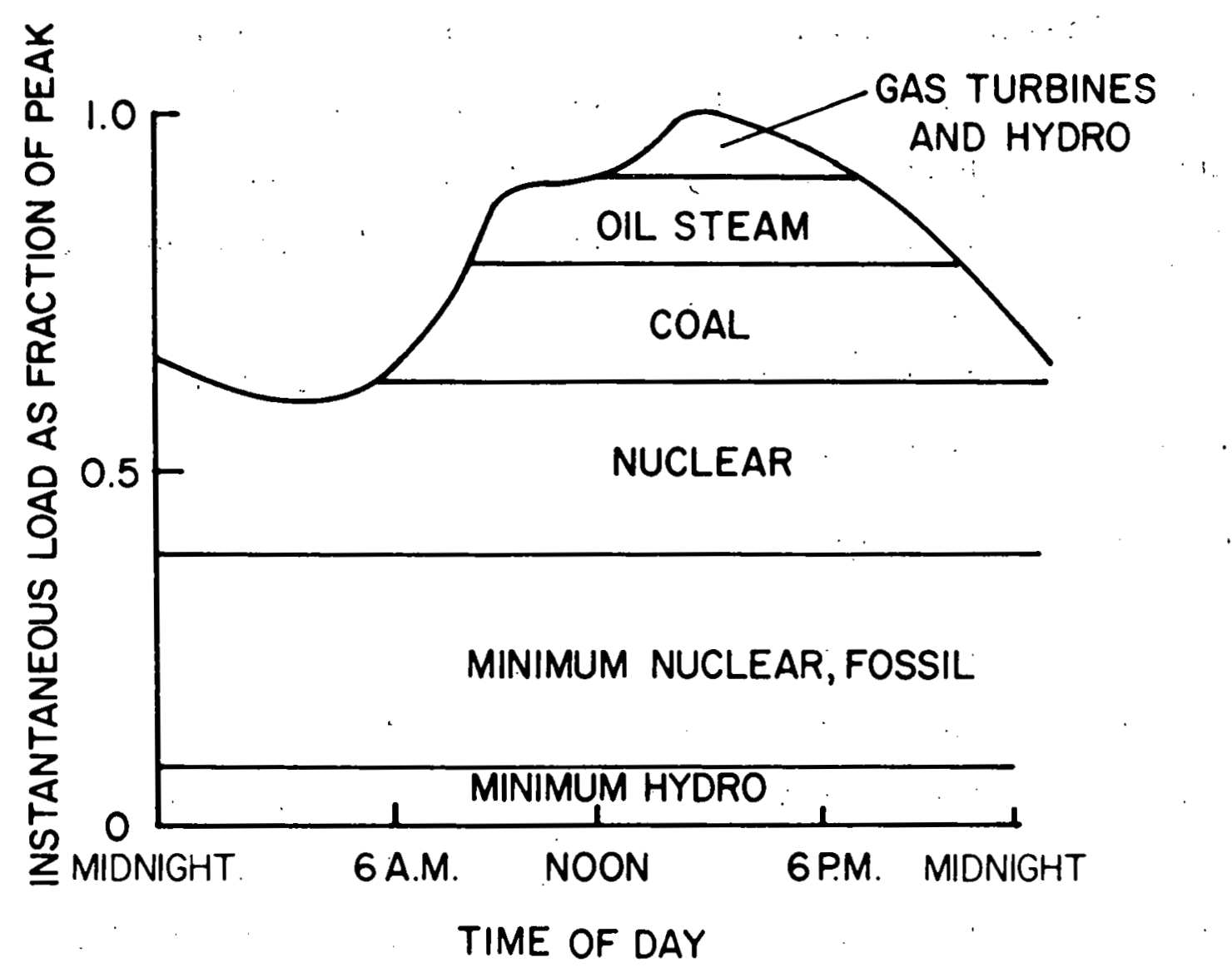

Figure 15. Scheduling of plants. 
a probalistic reliability analysis with an economic optimization routine in order to select the optimum schedule for capacity expansion. These programs are commonly employed by utilities today and have largely supplanted the simpler load duration curve type analysis. However, the basic principles upon which these programs are based are the same as those in the analysis presented in this section.

ANALYZING THE ECONOMICS OF WIND POWER

An economic evaluation of wind power in a utility context involves a comparison of the total cost of wind turbines to a utility with the "value" of wind power (the total monetary. savings that results from the displacement of conventional power). The determination of value requires that besides computing the monetary savings resulting from decreased fuel consumption, additional savings that might be achieved due to changes that can be made in the purchases of conventional generating equipment must be accounted for. A utility purchasing wind machines will usually be able to alter both the net capacity of and the type of conventional generating units that it would otherwise have purchased and experience monetary savings on both counts. These capacity related savings generally increase the value of wind power to utilities above the levels computed from fuel savings alone.

Because the output of a wind machine is not controllable by a utility, a wind machine cannot be treated like a 
conventional plant in utility analytical methods; since windpower will contribute haphazardly to the utility's generation during peak, intermediate and base load periods, it will displace power from a variety of conventional plant types in a complex fashion. Except in unusual circumstances, a simple comparison of the unit cost of electricity* from a wind machine with the unit cost from any one conventional plant type is likely to be misleading. A detailed analysis of the substitutions in power generation that would take place if wind machines were incorporated into a utility is required to yield an accurate estimate of the value of wind machines.

One method that has been employed for the analysis of wind power has been to treat the electrical output from a wind machine array as a negative load to be subtracted from the true load experienced by the utility. As shown in Figure 16, the resulting "net" load is then treated in a conventional manner in conducting planning and dispatch analyses. A schematic of an annual load duration curve, that might be computed from the time dependent "net" load over a year (i.e., hour-byhour true load minus wind power output) is shown in Figure 17. When the procedure outlined in Figure 13 is carried out on this net load duration curve, it can provide a qualitative picture of the effect of adding wind generators on the economical1y optimal allocation of conventional capacity. Figure 17 demonstrates that, if wind generators are added to a

\footnotetext{
*I.e., the total annual costs divided by the total annual electricity generated.
} 


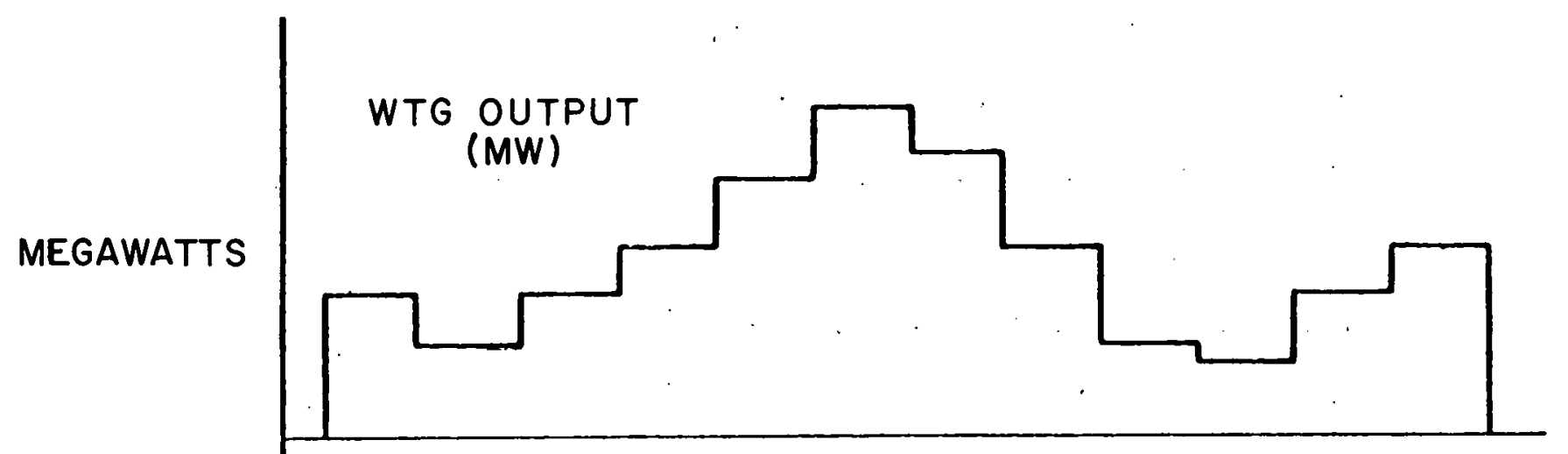

\section{MEGAWATTS}

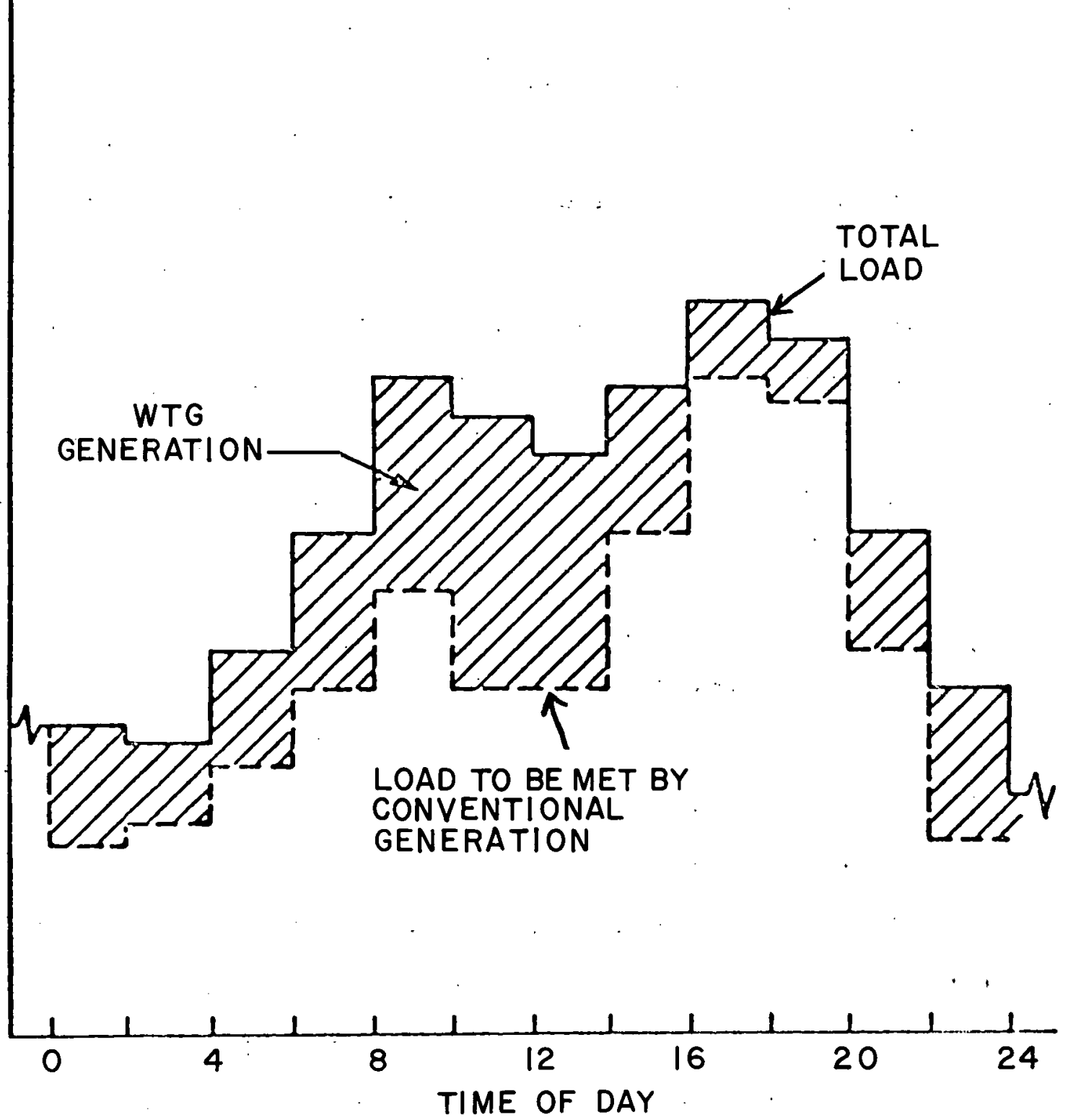

Figure 16. Treatment of wind generated power as a negative load: 
CONVENTIONAL

CAPACITY

ALLOCATION

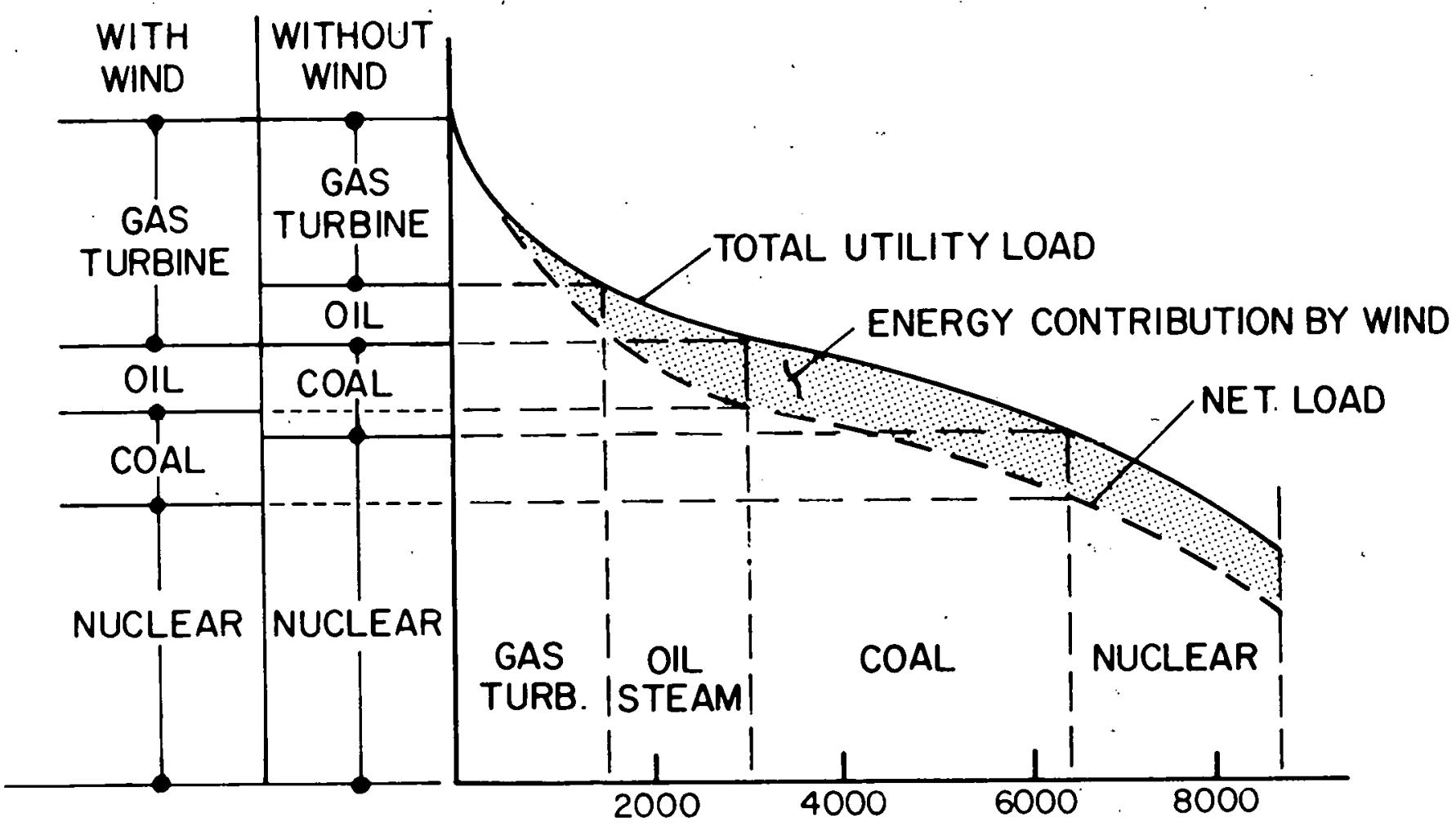

HOURS PER YEAR

Figure 17. Load duration curve method applied to the analysis of wind power. 
utility, the optimal allocation of baseload capacity tends to decrease while the optimal allocation of peaking capacity increases. This result has important economic consequences for the utility because peaking units cost much less on a unit capacity basis than baseload units and consequently, there are investment savings in conventional plants associated with the purchase of wind turbines.

Although valuable for providing qualitative insights, the analytical technique based on load duration curves cannot be relied on to provide credible quantitative results regarding the economically optimal and technically appropriate changes in capacity associated with the introduction of wind power into a utility. The reason for this is that the empirical rules that are used to refine the load duration curve results in order to incorporate dispatching, reliability and other considerations are implicitly based on the periodic nature of the load (recall the weekly load cycle in Figure 9). The subtraction of the wind power output from the timę-dependent load curve destroys the regular weekly cyclic character of the load curve and the existing empirical rules are no longer necessarily valid. To obtain a realistic assessment of the effect of adding wind machines, the results of the negative load method must be augmented by additional analyses which explicitly account for wind variation. Alternatively, techniques must be employed which analyze the load, conventional generation, and wind power output simultaneously and in a 
chronological fashion. These latter techniques have the virtue of being conceptually more straightforward, but they are cumbersome and difficult to use in practice.

One study which has tried to advance beyond the simplified load duration curve-negative load method was conducted by the General Electric Company which analyzed the economics of wind power with a computer simulation model. Given information about a utility system, future fuel and plant costs, and plant reliability, the computer model chooses an economically optimal capacity addition schedule. Plant reliability is accounted for by a probablistic "loss of load" computation which determines whether or not an assumed combination of plants can provide a level of service that meets the required criterion for reliability. For use in this model, wind power was modelled as a conventional plant with a high forced outage rate. The forced outage rate of wind power was computed on a monthly basis from historical wind velocity statistics. The energy contribution of the wind system was also computed from historical statistics and was modelled as a contracted purchase of electrical energy from another utility. In this way, fuel displacement could be properly computed. Results of the General Electric study are presented in a later section.

Another study currently in progress, conducted by the Aerospace Corporation, ${ }^{10}$ is employing a very detailed probabilistic model of the wind contribution to the utility's given system. In this study, the range in the level of power output from the 
wind array is divided into a number of discreet steps and the probability of the output having the value at each step is computed for each hour of the day for each month of the year from historical statistics. This matrix of probabilities is then incorporated into a loss-of-load computation which is used to determine an appropriate conventional capacity expansion schedule assuming that the wind machines are purchased.

The studies just described were specifically designed to incorporate the variable character of the wind directly into the basic study method. From studies of this type, a realistic assessment of the economic value of wind power to utilities is beginning to emerge. Some initial results from these studies are presented in a later section.

\section{A COMMENT ON "CAPACITY CREDIT"}

Although the term "capacity credit" does not have a welldefined meaning in a power systems context, it has been used in reference to wind and solar generated electricity to refer to the magnitude of the conventional equipment capacity that can be replaced by a unit of capacity from these variable sources. In some cases, it is assumed that the credited capacity of wind power is zero; i.e., wind power is so unreliable that, for all practical purposes, no decrease in the conventional capacity otherwise needed is possible. The wind generated energy is then said to contribute as a "fuel, saver" such that its contribution to the utility is measured only by the 
fuel not consumed when wind power is available. ${ }^{6,11}$ The economic value of wind machines is then computed as the cost of this "saved fuel."

Although these statements may seem disarmingly straightforward to the uninitiated, the way in which the "capacity credit" and "fuel saver" concepts are usually used is based on an overly simplistic view of utility operations. "The complexities of utility systems that result from the variety of conventional generators employed, each of which has a different combination of reliability, thermal inertia, efficiency vs. load characteristics, and fixed vs. operating costs are completely ignored by lumping all types of capacity into one generalized capacity credit variable. A fundamental problem with the use of these concepts is that simplified statements regarding the technical character of utilities are used to substitute for rigorous technical/economic analyses. The "no capacity credit" assumption ignores the fact that it is possible for a utility to save considerable monies in capital investments by purchasing peaking type generators (low fixed charge, high operating cost units) instead of expensive base load generators (high fixed charge, low operating cost units) while retaining the same total amount of conventional capacity. Such a shift would make sense when combined with the purchase of wind generators if it were determined that the extra peaking type units could be used primarily to provide the needed level of system reliability while burning relatively little fuel. In 
this case, the total cost of wind generators would be offset by some combination of fuel and capital expenditure savings even though it was assumed that no net "capacity credit" was assigned to the wind machines. In other words, there is no direct relationship between "capacity credit" and utility economics, and it is utility economics, taken in the context of technical and institutional constraints, which are ultimately of interest in making decisions regarding capacity purchases.

Since most utilities own and plan purchases of a variety of generating unit types, the substitution of wind power for conventional generation generally involves changes in the purchase or retirement of several different types of conventional units. Due to differences in the reliability of different types of generating units, they cannot be substituted for one another on a kilowatt for kilowatt basis while retaining a constant level of system reliability. Thus the hypothetical "capacity credit" - the net reduction in all conventional capacity due to the use of wind power - will differ from one utility to another depending on previously existing equipment and the new equipment purchase schedule that would otherwisc have been followed. It is not dependent only upon wind characteristics.

A computation of the economic value of wind power, based upon the wind characteristics, cost structure for conventional power generation, and reliability constraints associated with 
a specific utility, provides a direct, meaningful measure of the competitiveness of wind power. "Capacity credit" is a confusing detour around this central question.

SOME INITIAL RESULTS

The results available to date regarding the economics of wind power use by utilities are general and preliminary and require elaboration by more detailed studies. Nevertheless, a few tentative conclusions have emerged that provide insights in to the role wind power might play in electric power generation.

The least expensive method of incorporating wind generators into a utility network is to feed the power directly into transmission grids whenever wind power is available without the use of separate storage or backup capacity dedicated only for the wind array. Other generating units in the system can be constantly adjusted to meet the difference between the total load on the system and the wind array output. Thus, a greater number of generating units capable of rapid changes in output (on time scales of minutes to hours), such as gas turbines, hydropower units, or storage devices such as batteries, are likely to be needed if wind machines are employed than otherwise; large steam units, with outputs constrained to vary slowly, cannot easily provide backup for wind generators. The additional peaking units would serve to provide reserve power for periods when wind outages coincide with peak loads. 
The availability of storage can alleviate dispatching problems arising from wind variability. However, storage and wind power are not as closely coupled as is sometimes believed. From a utility perspective, storage units are simply a method of providing peaking capacity and, as such, must compete with alternative peaking devices in any application. This is no less true in the case of providing backup for wind power than for any other application in which rapid response, low load factor capacity is needed. Storage units serving each windmill, or even each windmill array, are an especially unlikely combination since this is not an optimal way for utilities to employ storage units; a utility investing in storage would use it to store low variable cost power for use during periods when the marginal variable costs were high, irrespective of the source of the low variable cost power. In general, wind power would be only one of several sources of the low variable cost power.

The value of windpower to a utility tends to decrease as the net capacity of the wind machines becomes a larger fraction of the total generating mix. There are several reasons for this: As the fraction composed of wind machines increases, 1) the conventional power displaced by the wind machines tends to be lower in cost (fractionally more of it is baseload), 2) the reserve requirements per unit of wind capacity increase, and 3) above some fraction of the total capacity, wind power is increasingly wasted during low load periods when large 
conventional plants are operating at their "minimum" part load capacities. Although the importance of these effects will differ from utility to utility, they are likely to limit the use of wind machines to $10 \%$ to $20 \%$ of a utility's total capacity.

An attractive combination of storage and wind power occurs in situations where dammed hydropower is currently being used for baseload power but which could be converted to peaking duty at a modest cost with the addition of more hydro turbine units. In particular, it has been suggested that hydropower authorities in the western United States, seeking new power sources to supply growing demand, might find wind power an attractive possibility. ${ }^{6,12}$ An additional factor favoring this application is the advantageous tax and financing regulations governing capital investments by public power authorities which tend to make capital intensive wind power systems relatively less expensive for the authorities than for private utilities.

Another favorable application for wind power is to provide power for islands or remote communities in high wind areas. Often power in such areas is supplied by diesel or turbine plants burning expensive fuels at low efficiency. The cost of power from these plants is high, making wind power more competitive in these areas than elsewhere and these rapid response units provide ideal backup power for wind systems.

As an example of some specific quantitative results, a General Electric Company study using a utility generation 
planning model (described in an earlier section) indicates that the value of wind power varies from $\$ 200-400$ per kilowatt depending upon the region of the country and the wind regime within that region. ${ }^{1}$ These results assumed 1975 fuel and plant costs and a mix of generating units characteristic of that expected in the 1980's. About half of the value could be attributed to fuel savings and half to capital expenditure savings for conventional capacity. In the year 2000 , with a significant fraction of the mix assumed to be composed of capital intensive nuclear units, capacity related savings are estimated to comprise about two-thirds of the value. Assuming a $20 \%$ increase in plant costs, and a fuel escalation rate of $2 \% /$ year for coal and uranium fuel, $5 \% /$ year for 0 il, and $15 \% /$ year for gas would increase the total value to about $\$ 700 / \mathrm{KW}$ for utilities in the Northeast United States if the machines were purchased in the near future. These latter assumptions provide a more realistic view of the value of wind power in the future than the 1975 values for plant and fuel costs.

Estimates of the production and installation costs of wind machines are very sensitive to assumptions regarding the cost of the first machine, the effects of production experience, and the effects of mass production. Most estimates range from \$500-700/KW for the one-hundreth unit produced when a $90 \%$ learning effect (cost drops by $10 \%$ for each doubling in cumulative production quantity) is assumed. The General Electric Company has contacted with the Department of Energy to construct the 
second of two $1.5 \mathrm{MW}$ wind machines for $\$ 1586 / \mathrm{KW}$ (in 1975 do1lars): Based on this cost, the $90 \%$ learning curve results in just under $\$ 700 / \mathrm{KW}$ for the one-hundredth unit. If these rough estimates for the production costs have any validity, then there is room for considerable optimism regarding the use of windpower by utilities in high wind areas.

To date, a comprehensive analysis of the environmental costs - both positive and negative - of wind power compared to conventional generating alternatives has not been made. Clearly, air and water pollution are likely to be reduced in the aggregate if wind power is used instead of additional conventional fuel burning power plants. At this time, the only significant negative "environmental" impacts of wind power that are known are television and microwave interference and "pollution" of the visual environment. If sited carefully, the latter problems can be minimized. Thus, a comprehensive comparative analysis is likely to reveal net non-economic benefits of wind energy.

\section{CONCLUSION}

Currently available information suggests that the costs of producing and installing wind generators compare favorably with the value of such machines to utilities in some regions of the country. It is safe to assume that there will be some use of wind power by U.S. utilities starting in the next few years in areas with favorable wind regimes and high fuel costs. 
Islands in high wind areas and hydropower authorities in the western U.S. are likely initial applications. The longer term potential of wind power will become more apparent as experience is gained in the production and operation of machines. 


\section{REFERENCES}

1. Wind Energy Mission Analysis, General Electric Company, Valley Forge Space Center, Report No. 76, SDS4267, February 1977 .

2. S. Linke, A. Teshome, P.D. Yehsakul, "A study of transmission and protection elements for wind energy generating systems," Brookhaven National Laboratory, Apri1 1978 .

3. P.C. Putnam, Power from the Wind, Van Nostrand Reinhold Company, New York, 1948.

4. G.E. Jorgenson, M. Lotker, R.C. Meier, D. Brierly, "Design Economic and System Considerations of Large Wind-Driven Generators," IEEE Power Engineering Society, Winter Meeting, January 1976.

5. T.S. Jayadev, "Windmills Stage a Comeback," IEEE Spectrum, November 1976, p. 45.

6. Wind Energy Mission Analysis, Lockheed California Company, Report No. LR27611, September 1976.

7. Design Study of Wind Turbines $50 \mathrm{KW}$ to $3000 \mathrm{KW}$ for Electric Utility Applications, General Electric Company, Valley Forge Space Center, ERDA/NASA-19403-76/2, February 1976 .

8. "Design Study of Wind Turbines $50 \mathrm{KW}$ to $3000 \mathrm{KW}$ for Electric Utility Applications," Kaman Aerospace Corporation, ERDA/NASA-19404-76/2, February 1976.

9. S.L. Macklis, "Systems Dynamics of Multi-Unit Wind Energy Conversion Systems Application," Proceedings of the Third Wind Energy Workshop, Vol. II (CONF 770921), Washington, D.C.

10. Walter C. Melton, "Loss of Load Probability and Capacity Credit Calculation for WECS," Proceedings of the Third Wind Energy Workshop, Vo1. II (CONF 770921), Washington, D.C., September 1977, p. 728 .

11. "Operational, Cost and Technical Study of Large Wind Power Systems Integrated with an Existing Electrical Utility," Southwest Research Institute, 1976.

12. C.J. Todd, P.L. Eddy, R.C. James, W.E. Howe11, "CostEffective Electrical Power Generation from the wind," Proceedings of the 1977 Annual Meeting, American Section, International Solar Energy Society, Orlando, Florida, June 1977 . 
